\title{
Tapping the Role of Microbial Biosurfactants in Pesticide Remediation: An Eco-Friendly Approach for Environmental Sustainability
}

\author{
Aman Raj', Ashwani Kumar ${ }^{1,2 *}$ and Joanna Felicity Dames ${ }^{2}$ \\ ${ }^{1}$ Metagenomics and Secretomics Research Laboratory, Department of Botany, Dr. Harisingh Gour University (Central \\ University), Sagar, India, ${ }^{2}$ Mycorrhizal Research Laboratory, Department of Biochemistry and Microbiology, Rhodes \\ University, Grahamstown, South Africa
}

OPEN ACCESS

Edited by:

Shashi Kant Bhatia,

Konkuk University, South Korea

Reviewed by:

Pankaj Chowdhary,

Indian Institute of Toxicology

Research (CSIR), India

Jay Shankar Singh,

Babasaheb Bhimrao Ambedkar

University, India

Abhishek Sharma,

Institute of Microbial Technology

(CSIR), India

${ }^{*}$ Correspondence:

Ashwani Kumar

ashwaniiitd@hotmail.com orcid.org/0000-0002-8453-3183

Specialty section:

This article was submitted to

Microbiotechnology,

a section of the journa

Frontiers in Microbiology

Received: 08 October 2021 Accepted: 22 November 2021 Published: 23 December 2021

Citation:

Raj A, Kumar A and Dames JF (2021) Tapping the Role of Microbial

Biosurfactants in Pesticide

Remediation: An Eco-Friendly

Approach for Environmental

Sustainability.

Front. Microbiol. 12:791723.

doi: 10.3389/fmicb.2021.791723
Pesticides are used indiscriminately all over the world to protect crops from pests and pathogens. If they are used in excess, they contaminate the soil and water bodies and negatively affect human health and the environment. However, bioremediation is the most viable option to deal with these pollutants, but it has certain limitations. Therefore, harnessing the role of microbial biosurfactants in pesticide remediation is a promising approach. Biosurfactants are the amphiphilic compounds that can help to increase the bioavailability of pesticides, and speeds up the bioremediation process. Biosurfactants lower the surface area and interfacial tension of immiscible fluids and boost the solubility and sorption of hydrophobic pesticide contaminants. They have the property of biodegradability, low toxicity, high selectivity, and broad action spectrum under extreme $\mathrm{pH}$, temperature, and salinity conditions, as well as a low critical micelle concentration (CMC). All these factors can augment the process of pesticide remediation. Application of metagenomic and in-silico tools would help by rapidly characterizing pesticide degrading microorganisms at a taxonomic and functional level. A comprehensive review of the literature shows that the role of biosurfactants in the biological remediation of pesticides has received limited attention. Therefore, this article is intended to provide a detailed overview of the role of various biosurfactants in improving pesticide remediation as well as different methods used for the detection of microbial biosurfactants. Additionally, this article covers the role of advanced metagenomics tools in characterizing the biosurfactant producing pesticide degrading microbes from different environments.

Keywords: pesticides, bioremediation, biosurfactants, hydrophobic, amphiphilic, metagenomics

\section{INTRODUCTION}

Soil pollution and land degradation are global problems originating from anthropological and natural sources (Malla et al., 2018). Urbanization and industrialization are the major sources of anthropological pollution while the use of chemical agents over the year for increasing crop production has led to the spread and accumulation of pollutants in the environment 
(Prihandiani et al., 2021). The most common contaminants in the soil are heavy metals, polycyclic aromatic hydrocarbons (PAHs), or pesticides. Pesticides are the chemical compounds used to kill unwanted pests such as bugs, flies, rodents, nematodes, fungal pathogens, and unwanted herbs to maintain plant health and increase agricultural production on limited land. Pesticides play an essential part in fulfilling the world food demand, though they are very hazardous, persistent, recalcitrant, and have extended half-life properties (Wattanaphon et al., 2008; Damalas and Eleftherohorinos, 2011; Odukkathil and Vasudevan, 2016; Lamilla et al., 2021). The most common pesticides used in India and the other countries are organophosphates like chlorpyrifos, profenofos, and glyphosate, with a few being organochlorine i.e., mirex, lindane, and chlordane (Lamilla et al., 2021). These organophosphorus and organochlorine pesticides are not targetspecific and have high biological stability in the soil and water bodies, polluting the ecosystem and making it pestilent for humans and other organisms such as pollinators, cattle, microbes, and aquatic organisms (Gennari et al., 2009; Sequinatto et al., 2013). Most organophosphate pesticides are classified as class II carcinogens with mutagenic, teratogenic, and carcinogenic effects on humans and other organisms (Bhatt et al., 2021a).

Looking at the grave danger of these toxic pollutants, there is an urgent need to deal with the harmful impacts of these toxic pesticides. Most physical and chemical pesticide removal methods have been in use for a long time. These methods include aeration, oxidation, excavation, incineration, landfilling, and storage, etc., which is labor-intensive, time-consuming, inefficient, and are not considered a sustainable method of remediation because they result in the generation of several secondary pollutants (Yoshikawa et al., 2017; Bhatt et al., 2021a). As a result, the implementation of bioremediation appears as the only answer to the issue mentioned above since it uses the ability of live indigenous microorganisms to clean the polluted site (Singh et al., 2011). Researchers worldwide are now trying to create the most cost-effective and long-term sustainable method for pesticide bioremediation. Microbial biosurfactantbased remediation is a natural, cost-effective, and environmental friendly method of on-site degradation of pesticides and other xenobiotics in which biosurfactants make pesticides bioavailable and microbes use them as a source of carbon, nitrogen, and phosphorous (Abouseoud et al., 2008; Luna et al., 2013; Chaprão et al., 2015; Odukkathil and Vasudevan, 2016; Bhatt et al., 2021b; Lamilla et al., 2021).

Biosurfactants are secondary metabolites produced by microorganisms used in many commercial applications due to their low toxicity, substantial biodegradability, and environmentally benign nature (Thavasi et al., 2011; Chaprão et al., 2015; Javee et al., 2020). Biosurfactants consist of both hydrophilic and hydrophobic regions that are formed from amino acids, as well as saturated and unsaturated fatty acids, respectively (Sharma et al., 2015; Bhatt et al., 2021b), which enables a reduction in surface tension and reaching out between two solvate molecules, thus accelerates the solvation of hydrophobic molecules in aqueous media for emulsion formation (Banat, 1995; Lamilla et al., 2021). It has been observed that hydrocarbon-contaminated areas are the best places to isolate biosurfactant-producing microorganisms to improve pesticide remediation (Singh et al., 2016; Tan and Li, 2018; Bhatt et al., 2021a; Lamilla et al., 2021). Figure 1 depicted the entry of pesticides into the food chain and the fate of pesticides and presented the mechanism of biosurfactant mediated pesticides degradation. Several published reports are available wherein biosurfactant producing potential of microbes have been utilized for bioremediation of pesticides.

Although most of the studies on bioremediation are done using single microbes (particularly culturable ones). Several reports suggest the microbial consortia enhances the remediation process compared to a single isolate (Pacwa-Płociniczak et al., 2011; Rasheed et al., 2020; Madamwar et al., 2021). While in several cases, the role of unculturable microbes is often ignored, and the underlying mechanism of microbes-mediated pesticides degradation is still unexplored (Singh and Gupta, 2018; Singh et al., 2019). The use of metagenomics to understand the underlying mechanisms of biodegradation in in-situ and to forecast degradation potential has yet to be studied. So, there is a lack of information about microbes' functional genes and genetic potential and their products like biosurfactants involved in degradation (Datta et al., 2020; Femina Carolin et al., 2020). Against this background, this article aims to give a comprehensive overview of the function of microbial biosurfactants in the remediation of pesticides. We also briefly addressed how improved metagenomics techniques might assist clean-up by providing access to uncultivable microbial species.

\section{EMERGING PESTICIDE POLLUTION: A GLOBAL CONCERN}

The tremendous demand to produce food at reasonable prices has forced farmers/growers to use chemical fertilizers and pesticides (Sarath Chandran et al., 2019). Organochlorine pesticides such as DDT (dichlorodiphenyltrichloroethane) and Gammaxene were used extensively during the second world war, but they proved to be an ecological disaster for the world and was banned by the United States in 1972 due to their toxic effects on the peripheral nervous system and its non-biodegradable nature. Several developed and developing nations banned the use of most organochlorine pesticides, including DDT (Mansouri et al., 2017; Peng et al., 2020). This led to increased demand for organophosphate pesticides such as malathion, parathion, monocrotophos, etc., due to their wide action spectrum and moderate toxicity (Narenderan et al., 2020; Parks et al., 2021). However, feeding the exponentially growing population on declining land area forced farmers to use these pesticides more than the recommended dose i.e., 1 U.S liquid pints per acre of land or 0.473 liters per acre of land area (Tchounwou et al., 2015; As per U.S. Environmental Protection Agency | US EPA, 2021). Insecticides, herbicides, rodenticides, and fungicides are among the most regularly used pesticides (Malla et al., 2018) and were used excessively during the green revolution to increase productivity and reduce crop loss (Sarath Chandran et al., 2019). Pesticide use is rising and negatively influencing the environment, particularly the soil quality and 
A

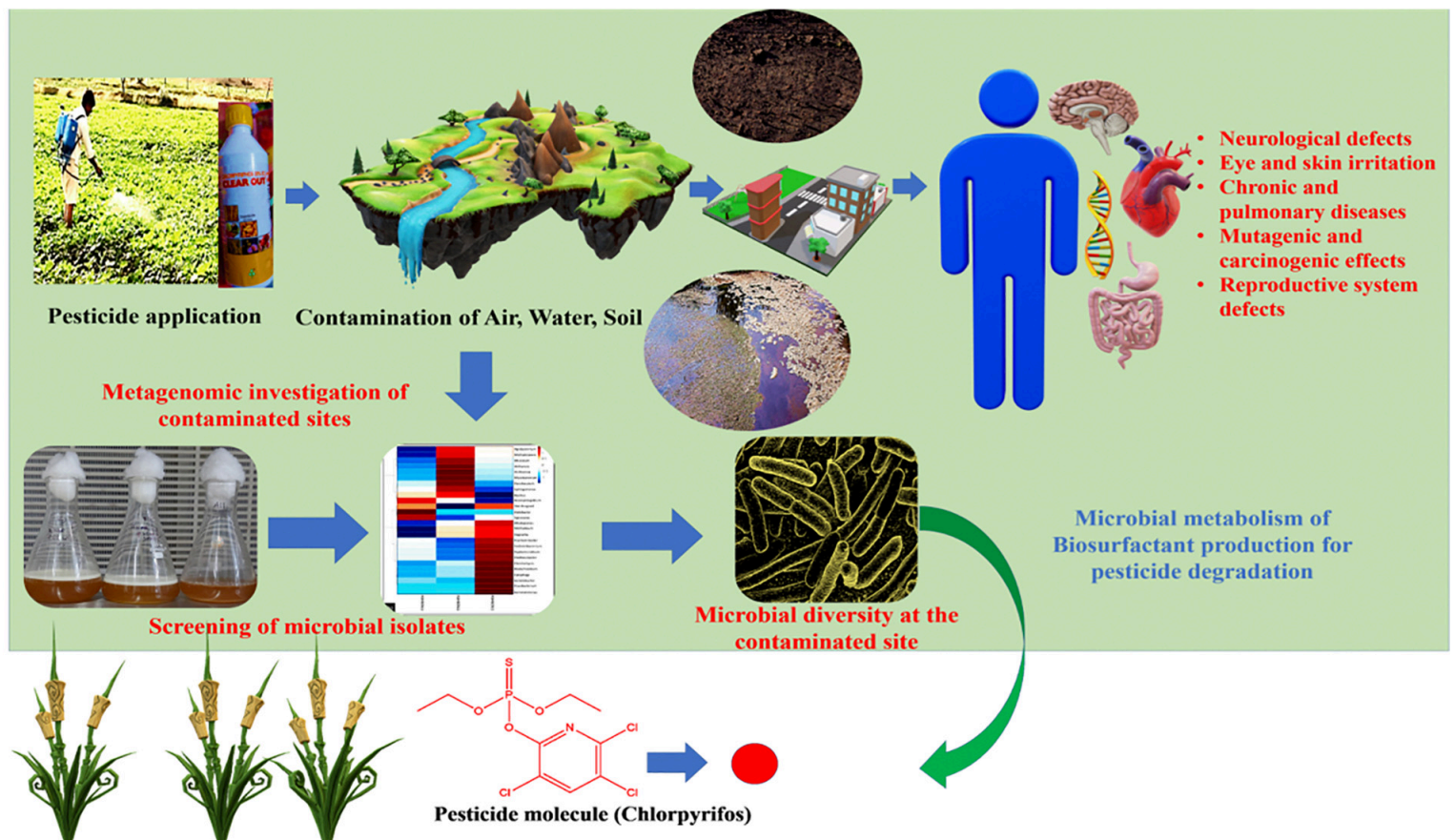

B

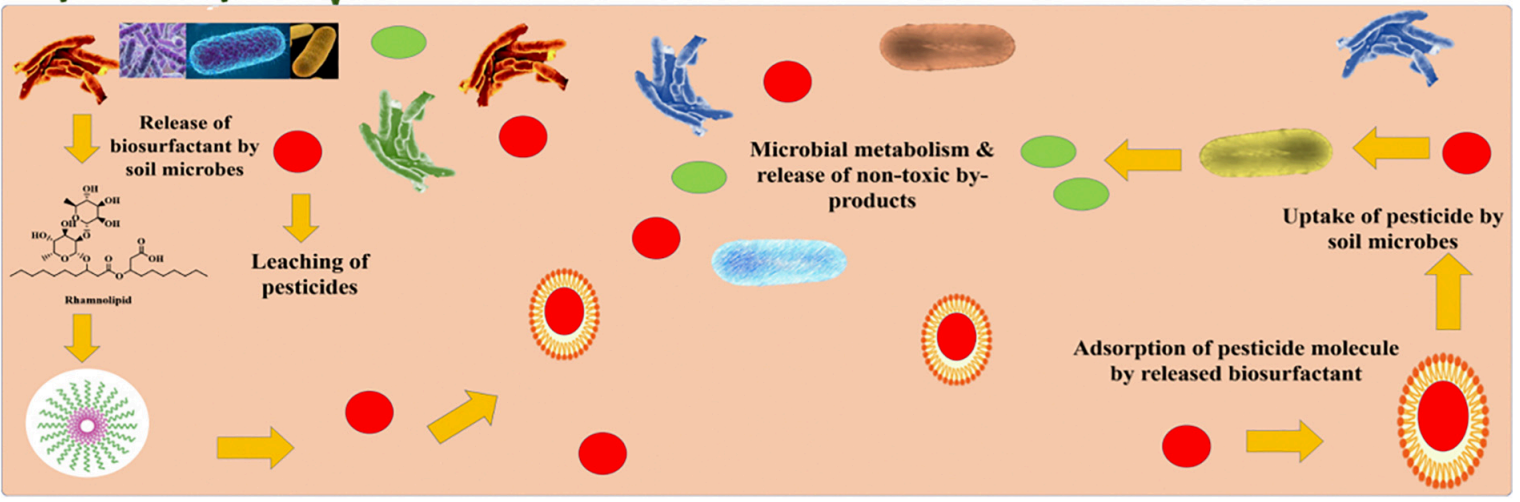

FIGURE 1 | (A) Shows the pesticide application in the field and its fate in the environment leading to contamination of air, water, and soil along with screening and isolation of microbes residing at the contaminated site for biosurfactant production (B) presented the mechanism of biosurfactant mediated pesticides degradation.

health (Rawat et al., 2020), as only 1\% of sprayed pesticides kill target species; the rest pollute the ecosystem by interacting with soil and generating more complex metabolites. For example, chlorpyrifos produces 3,5,6-trichloro-2-pyridinon (TCP), an antimicrobial metabolite that kills beneficial soil microorganisms and due to its eco-toxicity, the United nation banned this pesticide in the year 2020. However, chlorpyrifos is extensively used in developing countries like India, Bangladesh, and Pakistan (John and Shaike, 2015; Shabbir et al., 2018; Kalyani et al., 2021). Pesticides strongly adsorb the soil's organic matter, which restricts its desorption. Most of the pesticides are non-polar compounds having hydrophobic properties and are insoluble in water (Bhatt et al., 2021b; Kalyani et al., 2021). Pesticides are highly recalcitrant on exposure to humans; they lead to several disorders related to the central nervous system as most of these chemicals inhibit acetylcholinesterase receptor activity, causing nerve damage. Apart from it, inhalation of pesticides leads to several respiratory disorders and these chemicals also have mutagenic and carcinogenic potential causing disorders related to fertility, excretory system, skin, and eye defects (Figure 1; Foong et al., 2020; Giri et al., 2020). According to reports on poisoning and the impact of synthetic chemicals on human health, numerous cases of intoxication of farmers, rural workers, and their families have occurred during pesticide applications. Unintentional poisonings kill an estimated 3,55,000 people annually and are related to excessive exposure and improper use of hazardous substances (Nayak et al., 2020).

\section{Pesticide Defilement Status: Indian Context}

Agriculture and allied sectors provide a living for most of India's population (57\%) (Hobbs et al., 2009). India stands second in pesticide consumption $(0.29 \mathrm{~kg} / \mathrm{ha})$ among all Asian continents 
(Sharma et al., 2020; FAOSTAT, 2021). Crop production in India fell short of the country's demand in the post-independent period (Sebby, 2010). The implementation of the green revolution revolutionized India's conventional comestible farming into capital intensive, modernized, surplus-producing agriculture, resulting in a 10 -fold increase in overall food grains production between 1960 and 2000 (Davies, 2003; Kannuri and Jadhav, 2018). High yielding varieties (HYVs) were deployed as a part of the green revolution and these HYVs relied on enormous amounts of nitrogenous fertilizers to provide the desired crop outputs to feed the ever-expanding India's population (Kannuri and Jadhav, 2018; Sharma et al., 2019; Mishra et al., 2020). Narrow heritable traits of high yielding varieties of rice and wheat, as well as monocropping and tropical Indian climate, resulted in significant susceptibility to pests and diseases, but persistent pesticide application resulted in pest resistance. This lead to an over-reliance on pesticides to reduce crop loss, leading to a dramatic increase in pesticide use in India i.e., from 154 metric tons in 1954 to 88,000 metric tons in 2000 , a 570 per cent higher in less than a half-century (Kumar et al., 2016; Bonvoisin et al., 2020). However, strict action was taken by the Indian government lead to a decline in pesticide consumption by the year $2015-16$ to about 58,634 metric tons from 88,000 metric tons in 2000 , but this figure is steadily increasing and has reached about 62,193 metric tons in the year 2020-21 (Figure 2) which is a real cause of concern (Gunnell and Eddleston, 2003; Statistical Database | Directorate of Plant Protection, Quarantine, and Storage | GOI, 2021).

An investigation carried out by a group of researchers on the Thamirabarani river system of southern India reported the bioaccumulation of organochlorine pesticides such as aldrin, dieldrin, endosulfan, endrin, and heptachlor in surface water, sediments and fishes and other aquatic flora and fauna. Organochlorines were detected with the help of GC-MS following QuEChERS protocol extraction and were in a concentration ranging from 0.001 to $34.44 \mu \mathrm{g} / \mathrm{l}^{-1}$ in surface waters to as high as 40.46-65.14 $\mu \mathrm{g} \mathrm{kg}^{-1}$ in different organs of fishes (Arisekar et al., 2018). Not only vegetables or crop plants are detected with pesticide residues. Even milk samples have been detected with traces of pesticides such as DDT, $\mathrm{HCH}$, endosulfan, and pyrethroids in the Kolkata and Nadia region

\section{PESTICIDE USAGE IN INDIA (2020-21) \\ Unit: Metric tonnes}

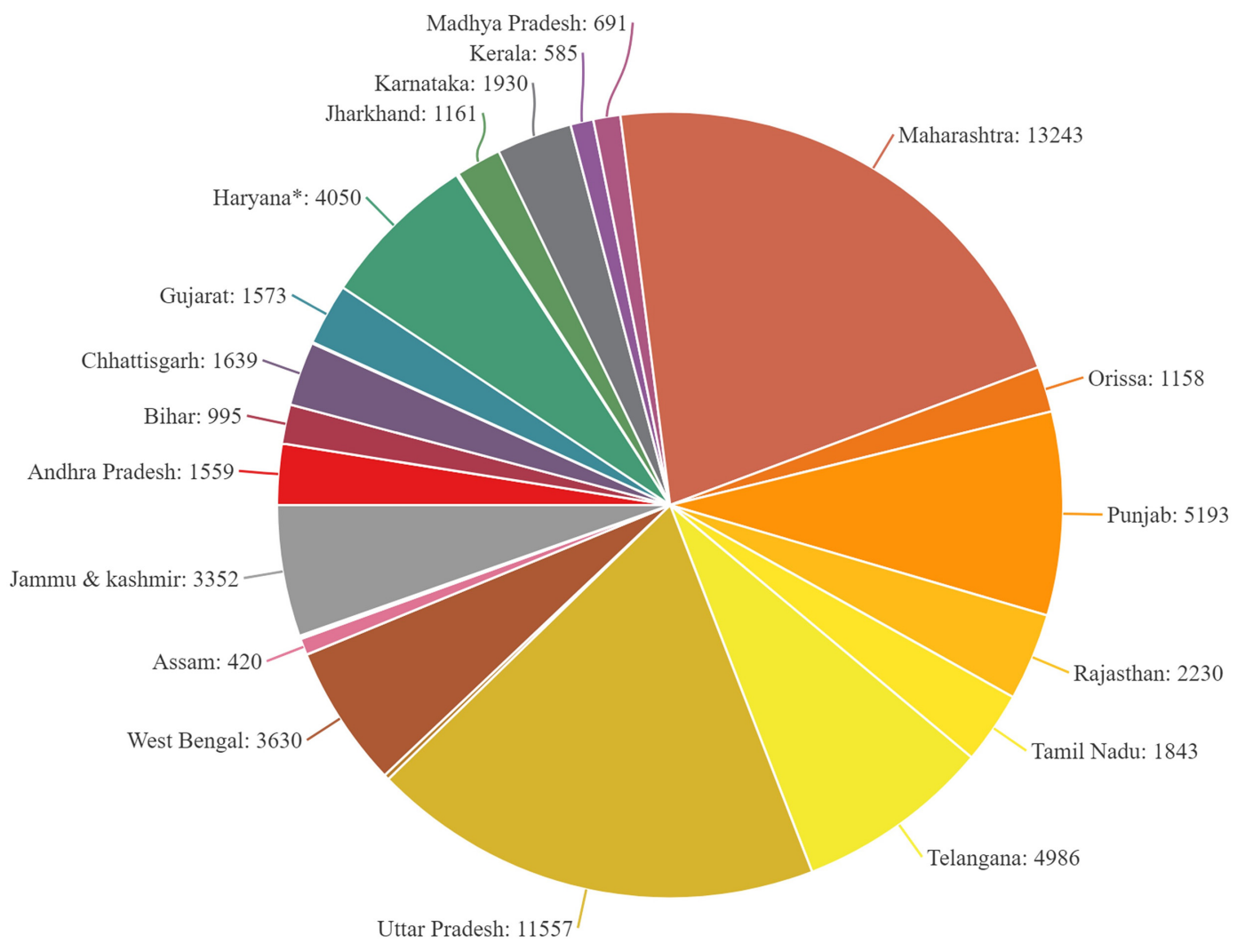

FIGURE 2 | Pesticide use in India (2020-21), [Unit: Metric tons (M.T)]. Pie-chart representing the average usage of pesticide by different Indian states in the year 2020-21. Highest usage among the states for which the pie-chart is made has been noted for Maharashtra with average usage of 13,243 M.T. while lowest for Andaman and Nicobar island with 1 M.T. Data were taken from statistical database of government of India, directorate of plant protection, quarantine and storage (Statistical Database | Directorate of Plant Protection, Quarantine and Storage | GOI, 2021). 
of West Bengal, India (Kumar et al., 2016; Anand et al., 2021; Ravula and Yenugu, 2021).

The Punjab region of India is highly affected by pesticide poisoning (Figure 2). In a study, out of 111 samples of human blood, $35 \%$ of the samples were detected with traces of pesticides like DDT, HCH, profenofos, monocrotophos etc. some samples were detected with a high level of $34.90 \mathrm{ng} \mathrm{ml}^{-1}$ (Sharma et al., 2020). Looking at the pesticide contamination status in India, there is an urgent need to develop techniques to deal with these toxic pollutants. Microbial biosurfactant based bioremediation seems to be the most sustainable way to eliminate these toxic compounds from soil and water bodies and to regain soil health.

\section{BIOSURFACTANTS: THE NEXT AGE COMPOUNDS IN PESTICIDE REMEDIATION AND THEIR TYPES}

Biosurfactants which are surface-active molecules produced naturally by microbial metabolism have gained popularity in recent times. In recent years, there has been a steady increase in the number of research papers focused on the isolation, characterization, and optimization of biosurfactants producing microbes (Das and Kumar, 2018; Olasanmi and Thring, 2018; Khanna and Pattnaik, 2019; Rawat et al., 2020). Biosurfactants are the type of "glycoconjugates (combination of glycoprotein and glycolipids)," and the study of its structure, function, and interaction with the living system is called "glycobiotechnology" (Messner et al., 2013; Enaime et al., 2019). Microbes produce some extracellular biosurfactants such as rhamnolipids, sophorolipids and exopeptidases, and glycollipopeptides. A wide variety of anionic and non-ionic synthetic surfactants (Triton X-100, tween-80, tergitol NP10, brij35, sodium dodecyl sulfate etc.) are in use for a long time to accelerate microbial activity whether in the area of xenobiotic remediation or biofuel production (da Rocha et al., 2010).

Furthermore, they are extensively used by pesticide industries as an emulsifiable concentrate in the pesticide formulation. However, synthetic surfactants are highly toxic, non-biodegradable, have low selectivity, high CMC value, and show antimicrobial activity (Bustamante et al., 2012; Yañez-Ocampo et al., 2017). Therefore, another reason for the popularity of biosurfactants is their advantages over their chemically manufactured counterparts, such as having a simpler structure than the synthetic equivalents, being environmentally friendly, and lesser toxicity (Rawat et al., 2020). On the other hand, biosurfactants can survive up to $10 \%$ salinity, but synthetic surfactants cannot. Other than their essential role in pesticide remediation (Tan and $\mathrm{Li}, 2018$ ), they are also used in various commercial products, including medications, cosmetics, cleaning agents, and the food sector (Santos et al., 2016).

Most microbes produced biosurfactants on their cell surface (amphiphilic molecules) as secondary metabolites at their stationary phase of growth (Soberón-Chávez et al., 2005; Moya Ramírez et al., 2015). These biosurfactants include glycoproteins, glycolipids, glycopeptides, glycosides, peptidoglycan, and lipopolysaccharides, which are the diverse forms of glycoconjugate-based biosurfactants (Varjani and Upasani, 2016; Bhatt et al., 2021b). One of the distinguishing features of biosurfactants is the hydrophilic-lipophilic balance (HLB), which determines the proportion of hydrophilic and hydrophobic elements in surface-active substances (Pacwa-Płociniczak et al., 2011). Biosurfactant activities are dependent on the concentration of surface-active molecules till the critical micelle concentration (CMC) is attained. Biosurfactant compounds form micelles, bilayers and vesicles at a concentration above CMC (Rasheed et al., 2020) and these micelles can reduce surface and interfacial tension and increase the solubility and bioavailability of hydrophobic pesticide molecules (Bhatt et al., 2021b). Surfactant efficiency is frequently measured using the $\mathrm{CMC}$, as efficient biosurfactants have a low $\mathrm{CMC}$, and require less biosurfactant to reduce surface tension (Pacwa-Płociniczak et al., 2011; Bhatt et al., 2021a,b). Micro-organisms may synthesize biosurfactants from various carbon sources, but Glycine max, Zea mays, Brassica napus, and Olea europaea can be employed to increase output (Bhatt et al., 2021b). Many researchers have tried producing biosurfactants from unconventional and agricultural-based raw materials; however, this approach has not yet been commercialized. These lipopeptides may be made from low-cost raw materials such as Saccharum officinarum, Zea mays, molasses, agricultural wastes, and others that are easily accessible in large numbers to be cost-effective (Hippolyte et al., 2018; Domínguez Rivera et al., 2019; Rawat et al., 2020). The structure and composition of the biosurfactant molecule and the role of biosurfactants in pesticide remediation is shown in Figures 3, 4.

\section{Types of Biosurfactants}

The majority of biosurfactant is either neutral or anionic while cationic biosurfactants are possessing amine groups. Longchain fatty acids make up the hydrophilic moiety, which can be any amino acid, glycogen, cyclic peptide, alcohol, or phosphate carboxyl acid, whereas monosaccharides, proteins, polysaccharides, or peptides make up a hydrophobic portion of the biosurfactant (Saharan et al., 2011; Bhati et al., 2019). Biosurfactants typically have a molar mass of 500-1,500 Dalton (Akbari et al., 2018). These are generally classified as per their chemical structure and microbiological derivation and are as follows:

The bulk of biosurfactants are glycolipids, carbohydrates with an ester group that connects them to long-chained aliphatic acids or hydroxyl aliphatic acids. Rhamnolipids, trehalolipids, and sophorolipids are well-known glycolipids (Rawat et al., 2020). Apart from glycolipids, lipopeptides, phospholipids, fatty acids, polymeric, and particulate biosurfactants are the other common types (Mnif and Ghribi, 2016; Kapoor et al., 2019). Figure 3 shows the structure and composition of the biosurfactant molecule.

Rhamnolipid consists of one or two rhamnose molecules linked to one or two hydroxyl decanoic acid molecules (de Oliveira Schmidt et al., 2021; Figure 3). Pseudomonas aeruginosa is said to produce the most rhamnolipids of any known microbial species, followed by Burkholderia species (Chong and Li, 2017; Ramirez et al., 2020). Recently, Marinobacter species and Pseudomonas mendocina have been isolated from the marine 

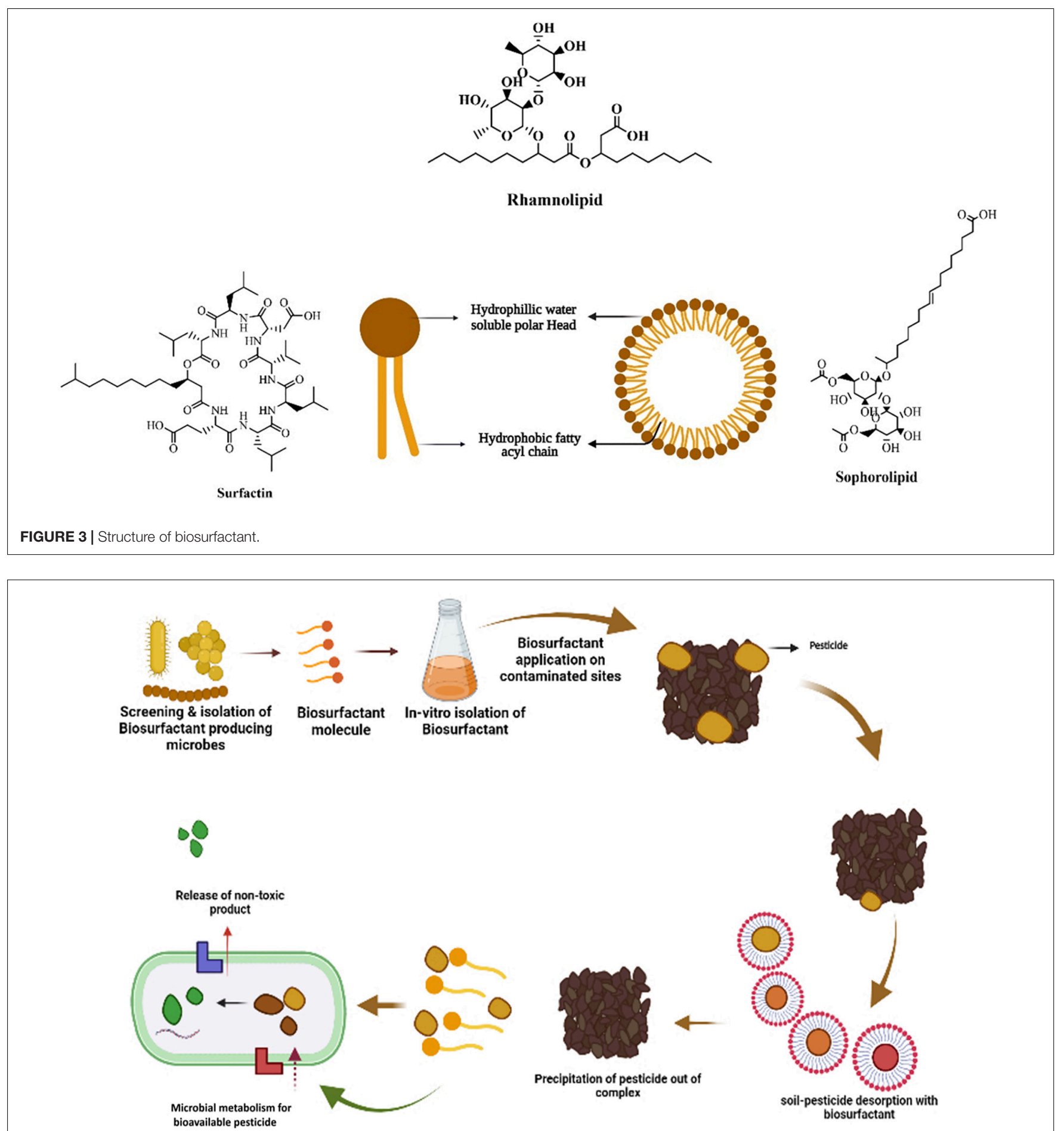

FIGURE 4 | In-vitro isolation of biosurfactant and its application at pesticide-contaminated sites. Further steps indicate the adsorption of biosurfactant with the soil-pesticide complex leading to desorption of pesticides from the soil particles. Microbial surfactants precipitate from the pesticide-biosurfactant complex, making pesticides bioavailable for the microbes for their further degradation.

environment and are an excellent producer of rhamnolipid (Tripathi et al., 2019; Twigg et al., 2019). Trehalolipids are extensively produced by Rhodococcus, Mycobacterium, Nocardia, and Corynebacterium species (Williams and Trindade, 2017;
Rawat et al., 2020). Arthrobacter species and Rhodococcus erythropolis are reported to produce trehalolipids that are nontoxic, versatile, and can reduce surface and interfacial tension in the culture broth. Trehalose lipids have been found to have 
enhanced surfactant activity in various situations and have been studied extensively (Williams and Trindade, 2017; Rawat et al., 2020). Sophorolipids are produced by non-pathogenic yeast species and are produced in large quantities $\left(400 \mathrm{~g} \mathrm{~L}^{-1}\right)$. These are made up of the glycosidic connection between sophorose, a dimer form of glycogen joined by $\beta-1,2$ linkage and a longchain hydroxy fatty acid (Figure 3). Many applications prefer the lactone form of sophorolipids, which comprises at least 6-9 different hydrophobic sophorolipids. Candida bombicola, Pseudomonas aeruginosa M408, and Starmerella bombicola are well-known sophorolipid producers (Rawat et al., 2020). Lipopeptides are polypeptide chains with varying lengths of $\beta$-hydroxy fatty acid and non-polar tails connected to them. Bacillus and Pseudomonas species are the most investigated lipopeptide producers, while Bacillus subtilis produces surfactin (Janek et al., 2021), the most potent lipopeptide known (Kumar et al., 2021a). Lipopeptides are the type of natural product produced by non-ribosomal peptide synthases (NRPS) (De Giani et al., 2021), which are huge multifunctional enzyme clusters (Williams and Trindade, 2017; Lamilla et al., 2021). Surfactin is considered one of the most potent biosurfactants (Meena et al., 2021) composed of cyclic lipopeptides with seven amino acid ringed structures linked to a fatty acid chain through lactone linkage (Figure 3; Onaizi, 2018; Sarwar et al., 2018). Table 1 summarizes the type of biosurfactant as well as the microbes that produce them and their roles in pesticide remediation. Fatty acids, Phospholipids, and Neutral lipids may be formed by a diverse group of microbial species that grow on various substrates, including n-alkanes (Varjani et al., 2021). Thiobacillus thioxidans is a well-known producer of phospholipids and has been reported to reduce sulfur elements from the soil. Corynebacterium lepus produces corynomycolic acid, which helps lower surface and interfacial tension at varied $\mathrm{pH}$ (Kosaric et al., 2018). Polymeric biosurfactants such as liposan, emulsan, alasan, lipomanan are the most investigated polymeric biosurfactants. Acinetobacter calcoaceticus RAG-1 produces an emulsan type of polymeric surfactant, which helps in emulsifying hydrocarbons in water (Uzoigwe et al., 2015). Liposan is synthesized by Candida lipolytica (Panjiar et al., 2017).

The biosurfactants listed above are representative of the main types of biosurfactants. Aside from that, many other kinds of biosurfactants and their uses will be described in detail in the next section concerning their application in pesticide remediation.

\section{Methods for Detection of Microbial Biosurfactants}

The discovery of new surfactant-producing microbial strains necessitates advanced microbial screening methods that should be both fast and reliable. In practice, employing a single screening approach for choosing biosurfactant-generating microorganisms has proved to be challenging to get reliable and consistent findings since biomolecules have a wide range of structural and functional characteristics (Adetunji and Olaniran, 2021). Therefore, several screening methods must be employed in parallel to pick a large number of biosurfactant synthesizers from a population of isolated bacteria to get the best results. These techniques are based on the surface tension or emulsification activity of the surfactant, and some of these methods are described in detail in the following section.

\section{Measurement of Surface Tension /Interfacial Measurement}

This is the most efficient and reliable method for screening microorganisms for biosurfactant production (Adetunji and Olaniran, 2021). Surface tension measures free energy per unit area at an interface or surface (Walter et al., 2010). The stalagometric method, Wilhelmy plate method, du-Nuong-ring method, pendant drop shape method, and axisymmetric drop shape analysis is used to measure the surface tension of culture supernatants directly using a tensiometer (Dusane et al., 2010; Satpute et al., 2010). Distilled water (DW) has a surface tension of $72 \mathrm{mN} / \mathrm{m}$. When biosurfactants are added to the DW, its surface tension is reduced. The ability of biosurfactants to reduce the surface tension of DW to less than $40 \mathrm{mN} / \mathrm{m}$ determines its effectiveness. The surface tension of water was reduced to around $30 \mathrm{mN} / \mathrm{m}$ by adding a rhamnolipid biosurfactant released by Pseudomonas aeruginosa (Dusane et al., 2010; Geetha et al., 2018; Adetunji and Olaniran, 2021).

\section{Drop Collapse Method}

It is one of the fastest and most straightforward techniques to conduct since it does not need specialized equipment and can be completed with a small sample (Jain et al., 1991). In this technique, surfactants are used to destabilize liquid droplets. On an oil-coated solid surface, drops of culture supernatant or cell suspension are dropped onto the surface. As long as the liquid does not include any surfactants, the polar water molecules are repelled from the hydrophobic surface, and the droplets do not become unstable (Walter et al., 2010). The spread or even collapse of the liquid drop occurs due to the reduction in force or interfacial tension between the liquid drop and the hydrophobic surface when the liquid includes surfactants. The surfactant concentration affects the stability of drops, which is linked to the surface and interfacial tension (Adetunji and Olaniran, 2021). However, despite its speed and simple procedure, this method has low sensitivity because a substantial concentration of surfaceactive chemicals is required to cause the aqueous drops to collapse on the oil or glass surface (Youssef et al., 2004; Batista et al., 2006; Yu and Huang, 2011).

\section{CTAB Agar Plate Method}

Extracellular glycolipids or other anionic surfactants can be detected using a CTAB (cetyltrimethylammonium bromide) agar plate method, a semi-quantitative screening method (Hazra et al., 2011). Siegmund and Wagner were the ones who developed this CTAB agar method for the detection of biosurfactant synthesizing microbes (Siegmund and Wagner, 1991). The microorganisms of interest are grown on light blue mineral salt, agar plate containing the cationic surfactant CTAB and the basic dye methylene blue. When the microbes release anionic surfactants on the plate, they combine with CTAB and methylene blue to generate a dark blue, insoluble ion pair (Rajesh et al., 2017). As a result, dark blue halos surround surfactant-producing 
TABLE 1 | Microbial biosurfactants and their role in pesticides degradation.

\begin{tabular}{|c|c|c|c|c|c|c|c|}
\hline Microorganism & $\begin{array}{l}\text { Biosurfactant } \\
\text { Produced }\end{array}$ & $\begin{array}{l}\text { Substrate for } \\
\text { Production }\end{array}$ & Pesticide Degraded & $\begin{array}{l}\text { Concentration of } \\
\text { Pesticide }\end{array}$ & Degradation (\%) & $\begin{array}{l}\text { Identification } \\
\text { technique }\end{array}$ & References \\
\hline $\begin{array}{l}\text { Pseudomonas, } \\
\text { Rhodococcus }\end{array}$ & Rhamnolipid & $\begin{array}{l}\text { Vegetable oil waste, } \\
\text { Zea mays waste }\end{array}$ & $\begin{array}{l}\text { Cypermethrin, } \\
\text { Chlorpyrifos }\end{array}$ & $2 \% w / v$ & $8-63 \%, 39-56 \%$ & $\begin{array}{l}\text { Emulsification, FTIR, } \\
\text { TLC, MALDI-TOF }\end{array}$ & $\begin{array}{l}\text { Nitschke and Pastore, } \\
\text { 2006; Aguila-Torres } \\
\text { et al., 2020; Lamilla } \\
\text { et al., 2021 }\end{array}$ \\
\hline Pseudomonas sp. & Rhamnolipid & Animal waste & Chlorpyrifos & $0.01 \mathrm{gl}^{-1}$ & $98 \%$ & $\begin{array}{l}\text { Gas } \\
\text { chromatography-mass } \\
\text { spectrometry (GC-MS/ } \\
\text { HPLC) }\end{array}$ & $\begin{array}{l}\text { Singh et al., 2009; Lima } \\
\text { et al., } 2011\end{array}$ \\
\hline $\begin{array}{l}\text { Pseudomonas } \\
\text { aeruginosa } \mathrm{CH} 7\end{array}$ & Rhamnolipid & Cassava flour wheat & $\beta$ - cypermethrin & $25-900 \mu \mathrm{g} \mathrm{L}^{-1}$ & $90 \%$ & Mass spectrometry & $\begin{array}{l}\text { Zhang et al., 2011; de } \\
\text { Andrade et al., } 2016\end{array}$ \\
\hline $\begin{array}{l}\text { Arthrobacter } \\
\text { globiformis }\end{array}$ & Rhamnolipid & Agro-industrial waste & DDT & $0.04 \mathrm{mg} / \mathrm{L}$ & $65 \%$ & - & $\begin{array}{l}\text { Bai et al., 2017; } \\
\text { García-Reyes et al., } \\
2018\end{array}$ \\
\hline $\begin{array}{l}\text { Pseudomonas } \\
\text { aeruginosa }\end{array}$ & Rhamnolipid & $\begin{array}{l}\text { Canola oil, } \\
\text { Agro-industrial waste }\end{array}$ & Endosulfan, Quinalphos & $\begin{array}{l}320 \text { mg/L, 10,000 } \\
\mathrm{mg} / \mathrm{L}\end{array}$ & $90 \%, 94 \%$ & $\begin{array}{l}\text { FTIR/TLC } \\
\text { Spectrophotometer }\end{array}$ & $\begin{array}{l}\text { Abbasi et al., 2012; } \\
\text { Nair et al., 2015; } \\
\text { Pérez-Armendáriz } \\
\text { et al., 2019; Briceño } \\
\text { et al., 2020; Bhatt } \\
\text { et al., 2021b }\end{array}$ \\
\hline $\begin{array}{l}\text { Pseudomonas sp. } \\
\text { chID }\end{array}$ & Rhamnolipid & Sunflower oil waste & Chlorpyrifos & 10 mg/L & $99 \%$ & FTIR spectra analysis & $\begin{array}{l}\text { Kaskatepe and Yildiz, } \\
\text { 2016; Singh et al., } \\
\text { 2016; Shabbir et al., } \\
2018\end{array}$ \\
\hline $\begin{array}{l}\text { Lysinibacillus } \\
\text { sphaericus IITR51 }\end{array}$ & Rhamnolipid & Soybean waste oil & Endosulfan and $\mathrm{HCH}$ & 50 and $100 \mathrm{mg} / \mathrm{L}$ & > solubility & - & $\begin{array}{l}\text { Bhatt et al., 2019; Gaur } \\
\text { et al., 2019; Lamilla } \\
\text { et al., 2021 }\end{array}$ \\
\hline $\begin{array}{l}\text { Pseudomonas } \\
\text { aeruginosa and } \\
\text { Sphingomonas sp. }\end{array}$ & Rhamnolipid & Agro waste & $\begin{array}{l}\text { Hexachlorocyclohexane } \\
(\mathrm{HCH})\end{array}$ & $40 \mathrm{mg} / \mathrm{L}$ & $95 \%$ & $\begin{array}{l}\text { FTIR, Emulsification, } \\
\text { GC-MS }\end{array}$ & $\begin{array}{l}\text { Manickam et al., 2012; } \\
\text { Das and Kumar, 2018; } \\
\text { Niu et al., } 2019\end{array}$ \\
\hline $\begin{array}{l}\text { Rhodococcus sp. } \\
\text { IITR03 }\end{array}$ & Trehalolipid & Soybean oil waste & $\begin{array}{l}\text { Dichlorodiphenyltri } \\
\text { chloroethane (DDT) }\end{array}$ & $282 \mu \mathrm{M}$ & $60 \%$ & $\begin{array}{l}\text { LC-MS (Liquid } \\
\text { chromatography-MS) } \\
\text { and chemical analysis }\end{array}$ & $\begin{array}{l}\text { Bages-Estopa et al., } \\
\text { 2018; Soares da Silva } \\
\text { et al., 2019; Bhatt } \\
\text { et al., 2021a }\end{array}$ \\
\hline $\begin{array}{l}\text { Burkholderia } \\
\text { cenocepacia BSP3 }\end{array}$ & Glycolipid & Frying oil waste & Parathion & $500 \mathrm{mg} / \mathrm{L}$ & Enhanced solubility & FTIR/chemical analysis & $\begin{array}{l}\text { Wattanaphon et al., } \\
\text { 2008; Schultz and } \\
\text { Rosado, } 2020\end{array}$ \\
\hline $\begin{array}{l}\text { Pseudomonas sp. } \\
\text { B0406 }\end{array}$ & Glycolipid & Soybean waste oil & Methyl parathion & - & > solubility & LC-MS, FTIR & $\begin{array}{l}\text { Cortés-Camargo et al., } \\
\text { 2016; Patowary et al., } \\
\text { 2017; García-Reyes } \\
\text { et al., } 2018\end{array}$ \\
\hline
\end{tabular}




\begin{tabular}{|c|c|c|c|c|c|c|c|}
\hline Microorganism & $\begin{array}{l}\text { Biosurfactant } \\
\text { Produced }\end{array}$ & $\begin{array}{l}\text { Substrate for } \\
\text { Production }\end{array}$ & Pesticide Degraded & $\begin{array}{l}\text { Concentration of } \\
\text { Pesticide }\end{array}$ & Degradation (\%) & $\begin{array}{l}\text { Identification } \\
\text { technique }\end{array}$ & References \\
\hline $\begin{array}{l}\text { Serratia } \\
\text { marcescens } \\
\text { UCP-1549 }\end{array}$ & Lipoprotein & Cassava wastewater & Organic pollutants & - & - & Mass spectrometry & $\begin{array}{l}\text { Casullo De Araújo } \\
\text { et al., 2010; de } \\
\text { Andrade et al., } 2016\end{array}$ \\
\hline $\begin{array}{l}\text { Paenibacillus sp. } \\
\text { D9 }\end{array}$ & Lipopeptide & Soybean oil waste & $\mathrm{HCH}$ & - & $49-65 \%$ & $\begin{array}{l}\text { TLC/FTIR Thin-layer } \\
\text { chromatography/ } \\
\text { Fourier transform } \\
\text { infrared spectroscopy, } \\
\text { Affinity chromatography }\end{array}$ & $\begin{array}{l}\text { Li et al., 2016; Jimoh } \\
\text { and Lin, 2019b; } \\
\text { Marcelino et al., } 2019\end{array}$ \\
\hline $\begin{array}{l}\text { Bacillus subtilis } \\
\text { MTCC } 1427\end{array}$ & Lipopeptide & Soybean oil waste & Endosulfan & $400 \mu \mathrm{g} / \mathrm{ml}$ & $100 \%$ & $T L C / \mathbb{R}$ & Bhatt et al., 2021b \\
\hline $\begin{array}{l}\text { Consortia of } \\
\text { Bordetella petrii IGV } \\
34 \text { and Bordetella } \\
\text { petrii II GV } 36\end{array}$ & $\begin{array}{l}\text { Unidentified } \\
\text { biosurfactant }\end{array}$ & - & Endosulfan & $3,400 \mathrm{mg} / \mathrm{L}$ & $100 \%$ & - & $\begin{array}{l}\text { Odukkathil and } \\
\text { Vasudevan, } 2016\end{array}$ \\
\hline $\begin{array}{l}\text { Pseudomonas } \\
\text { aeruginosa B1, } \\
\text { P. fluorescens B5, } \\
\text { P. stutzeri B11 and } \\
\text { P. putida B15 }\end{array}$ & Exopolysaccharides & Saw dust & 2,4-D & $0.2 \% \mathrm{v} / \mathrm{v}$ & $70 \%$ & HPLC & $\begin{array}{l}\text { Onbasli and Aslim, } \\
2009\end{array}$ \\
\hline $\begin{array}{l}\text { Bacillus algicola, } \\
\text { Rhodococcus soli, } \\
\text { Isoptericola } \\
\text { chiayiensis }\end{array}$ & Rhamnolipids & $\begin{array}{l}\text { Potato process effluent, } \\
\text { corn steep liquor }\end{array}$ & Crude oil & - & $65 \%$ & FTIR, LC-MS, GC-MS & $\begin{array}{l}\text { Sachdev and } \\
\text { Cameotra, 2013; Lee } \\
\text { et al., } 2018\end{array}$ \\
\hline $\begin{array}{l}\text { Actinomycetes, } \\
\text { Bacillus, } \\
\text { Pseudomonas, } \\
\text { Rhodococcus }\end{array}$ & $\begin{array}{l}\text { Lipopeptide, } \\
\text { sophorolipid, glycolipid }\end{array}$ & Date molasses & Organic pollutants & - & 63-84.6\% & $\begin{array}{l}\text { Lyophilization, Pedant } \\
\text { drop method }\end{array}$ & $\begin{array}{l}\text { Al-Bahry et al., 2013; } \\
\text { Jimoh and Lin, 2019a }\end{array}$ \\
\hline
\end{tabular}


microbes (Adetunji and Olaniran, 2021). This method is simple, selective for anionic surfactants, and can be performed on agar plates or liquid broth with various substrates and temperatures. Still and all, CTAB is toxic and prevents the growth of several bacterial colonies (Walter et al., 2010).

\section{Oil Spreading Assay}

In the oil spreading method, crude oil $(10 \mathrm{ml})$ is added to distilled water $(40 \mathrm{ml})$ in a Petri plate, resulting in a thin layer of oil (Alyousif et al., 2021). Following that, culture supernatants $(10 \mathrm{ml})$ are introduced to the oil-water interface (Soltanighias et al., 2019; Dayamrita et al., 2020). The presence of surfactant in the culture supernatant is demonstrated by the displacement of oil and the emergence of a clear zone. Surfactant activity is proportional to the diameter of the clear zone on the oil surface (Sarwar et al., 2018; Adetunji and Olaniran, 2021). The oil spreading method is a quick, accurate and dependable way to identify the synthesis of biosurfactants by a variety of microbes (Walter et al., 2010; Hazra et al., 2011; Hasanizadeh et al., 2017).

\section{Penetration Assay}

This assay is based on the color shift that occurs when two insoluble phases come into contact. For this experiment, the wells of 96 well micro-plate are filled with $150 \mu \mathrm{l}$ of a hydrophobic paste made up of oil and silica gel. $10 \mu \mathrm{l}$ of oil is poured over the paste. The culture's supernatant is then dyed by adding $10 \mu \mathrm{l}$ of a red staining solution to $90 \mu \mathrm{l}$ of supernatant. The colored supernatant is applied to the paste's surface (Maczek et al., 2007). The hydrophilic liquid will break through the oil film barrier into the paste if a biosurfactant is present. Within $15 \mathrm{~min}$, the silica will shift from more apparent red to cloudy white as it enters the hydrophilic phase. The described effect is based on the fact that when biosurfactants are present, silica gel transitions from hydrophobic to the hydrophilic phase faster. The supernatant without biosurfactants will become hazy but remains red to crimson red (Walter et al., 2010; Singh and Sedhuraman, 2015; Touseef and Ahmad, 2018).

Apart from it, there exist several other methods for detection of biosurfactants producing microbes such as microplate assay (Walter et al., 2010), emulsification capacity assay (Cooper and Goldenberg, 1987), BATH (bacterial adhesion to hydrocarbon) assay (Rosenberg et al., 1980; Nayarisseri et al., 2019; Dayamrita et al., 2020), salt aggregation assay (Ismail et al., 2018), and blood hemolysis assay (Adetunji and Olaniran, 2021).

\section{APPLICATION OF BIOSURFACTANTS AND THEIR MECHANISM OF ACTION IN PESTICIDE REMEDIATION}

Pesticide contamination is a significant problem. The use of biosurfactants for pesticide biodegradation has recently gained popularity. According to ZION market research and global market insights, the worldwide biosurfactant industry is projected to reach $\$ 2.4$ billion by 2025 (Lai et al., 2009; Sun et al., 2015). The biosurfactant market is anticipated to grow as the pesticide business grows and consumers become more health-conscious (Rawat et al., 2020). The most crucial role that biosurfactants play is the dissociation of toxic pesticide molecules from the soil or water molecules, thus making it bioavailable for the microbes to speed up the remediation process (Figure 5; Inakollu et al., 2004; Whang et al., 2009; Rasheed et al., 2020). Desorption from soil particles leads to a reduction in surface tension, thus enhancing the mechanism of degradation (Singh et al., 2007; Twigg et al., 2019). The probable interaction used for pesticides bioremediation by biosurfactants includes electrostatic interactions, counter-ion binding, ion exchange, and precipitation-dissolution (Banat et al., 2010; Patowary et al., 2017; Xu et al., 2018).

Biosurfactants enhance the surface area of hydrophobic pesticides, increasing their solubility in soil and water by inducing emulsification of pesticide molecules (Bhatt et al., 2021b). The thumb rule of bioremediation is that the more the amount of pesticide that is water-soluble, the greater the amount of pesticide bioavailable to microorganisms. Surface-active apolar flocculating molecules such as biosurfactants, which produce emulsions at and above their critical micellar concentration, may enhance the separation of hydrophobic pesticides from the aqueous phase by creating emulsions at and above their critical micellar concentration (CMC). When pesticides are released into the environment, they become more bioavailable to possible degraders, which may help alleviate the worry about pesticide contamination of soil and water bodies (Zhou et al., 2011; Moya Ramírez et al., 2015). As a result, the soil becomes free of pollutants, productive, and suitable for crop cultivation (Fenibo et al., 2019; Jimoh and Lin, 2019a). The overall mechanism of soil, microbes and pesticide interaction is shown in Figure 5.

Rhamnolipids are the most widely used biosurfactants in industrial and environmental clean-up applications. The potential of rhamnolipid in bioremediation has been extensively studied in Pseudomonas and Burkholderia species (Varjani and Upasani, 2016). Rhamnolipids obtained from Pseudomonas aeruginosa enhance biodegradation of herbicide trifluralin and insecticide chlorpyrifos in the contaminated soil-water bodies (Singh et al., 2016; Tan and Li, 2018). It has been reported that the presence of glycolipid type of biosurfactant obtained from Pseudomonas species enhances solubilization of methyl parathion and endosulfan (GarcíaReyes et al., 2018). With around $100 \mathrm{gL}^{-1}$, Pseudomonas aeruginosa is regarded as the top rhamnolipid producer and it produces two forms of rhamnolipids in liquid suspension i.e., mono and di-rhamnolipid (Varjani and Upasani, 2016) by rhamnosyl transfer enzymatic reaction with the help of rhamnosyltransferase enzyme (Soberón-Chávez et al., 2005; Varjani and Upasani, 2017). The hydrophobic and hydrophilic components of the rhamnolipid are formed due to a series of enzymatic processes that take place in microbes. After synthesis, the two halves of the lipid are linked together to form mono- and di-rhamnolipids, respectively (Bhatt et al., 2019). A rhamnolipid was formed from an axenic culture of Pseudomonas putida strain DOT-T1E, which aided in the bioremediation of chlorinated phenols (Maia et al., 2019). The trapping of the chlorophenol in the biosurfactant 


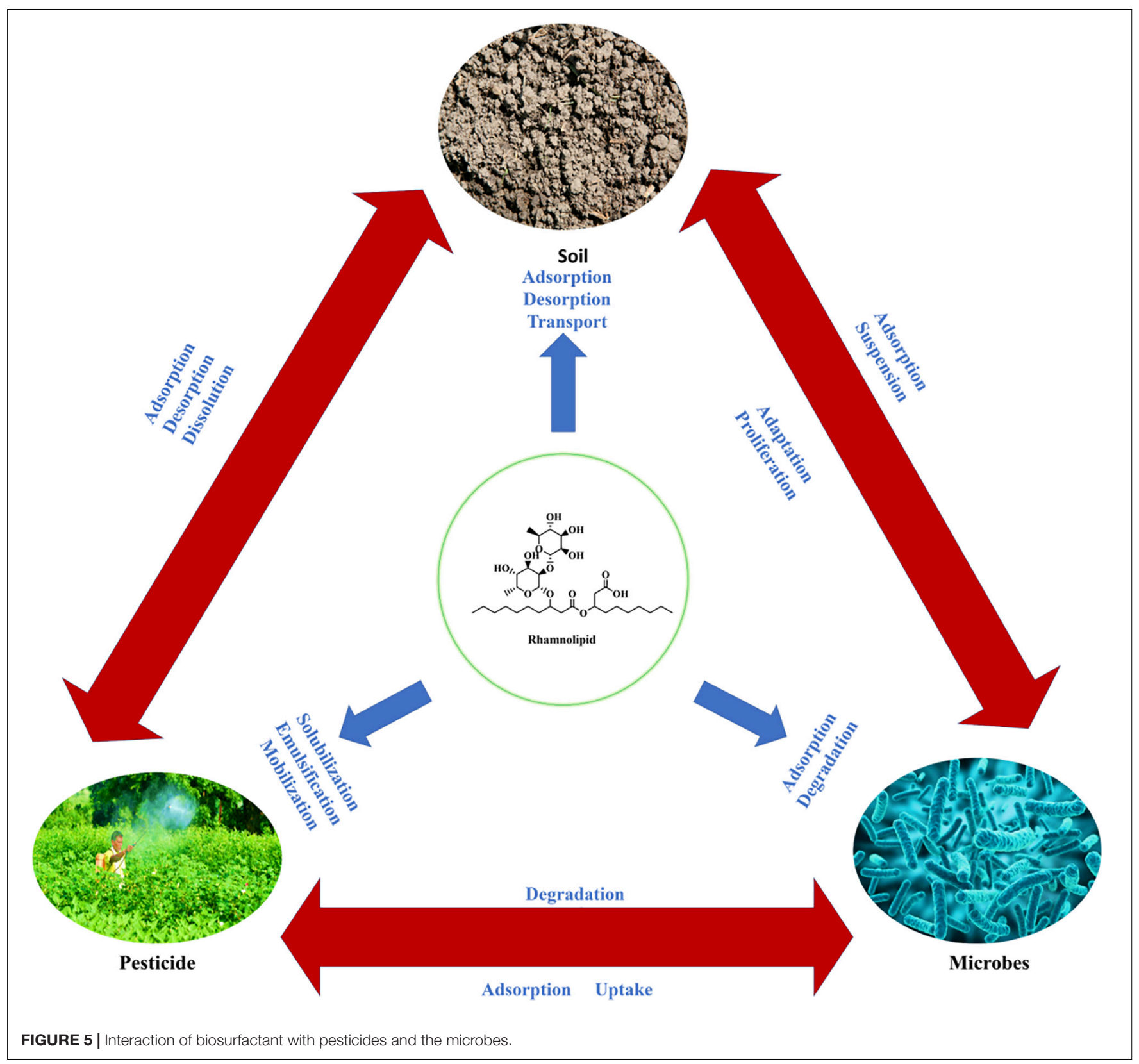

micelles, as well as the hydrophobic connection between these two types of molecules, are at the heart of this action. Likewise, actinobacteria-formed biosurfactant accelerates the bioremediation of xenobiotics (Sponza and Gok, 2011). In the bioremediation of carbendazim with Rhodococcus species D-1, rhamnolipids were found efficient. With the highest bioremediation efficiency, the rhamnolipid altered carbendazim degradation in a concentration-dependent manner. It aided carbendazim transesterification and favorable cell surface modification, allowing it to enter Rhodococcus species D-1 cells, which were degraded (Bai et al., 2017). Glucolipid type of biosurfactant produced by Burkholderia cenocepacia BSP3 complements the solubilization of pesticide (Bustamante et al., 2012). Biosurfactants that spontaneously break down the pesticides are good for the environment and are considered environmentally benign (Jezierska et al., 2019).

Rhizospheric bacteria's have been reported to play a key role in the degradation of pesticides, accelerating the breakdown as seen during biosurfactant biosynthesis (Bordoloi and Konwar, 2009; Singh, 2015; Dos Santos and Maranho, 2018). The amount of biosurfactant is also vital for microbial development. High quantities of these biosurfactants inhibit microbial growth and breakdown. These findings may not apply to all microbial strains. A study shows that biosurfactant addition increased $30 \%$ endosulfan degradation with the help of Bacillus subtilis MTCC 1427 in the soil and aqueous solution (Zhou et al., 2011). Endosulfan isomers were found to have more significant mobilization and accessibility in the presence of biosurfactant, 
which could be due to pesticide solubilization or improved attraction for micro-organism cells. Due to the formation of rhamnolipids by $P$. aeruginosa, the soil adulterated with endosulfan showed accelerated degradation after 7 days of the experiment (Madamwar et al., 2021). The published article indicated that the Pseudomonas strain BO406 produced a raw extract of a biosurfactant (glycolipid) that aided in the solubilization of endosulfan (García-Reyes et al., 2018). The strain of Lysinibacillus sphaericus IITR51 was used by researchers to develop a thermostable rhamnolipid biosurfactant capable of increasing the solubility of the highly hydrophobic pesticides such as endosulfan and $\mathrm{HCH}$ (hexachlorocyclohexane) (Manickam et al., 2012; Gaur et al., 2019). A strain of Pseudomonas SB can produce a biosurfactant that enhances DDT breakdown. Rhamnolipid has been reported to increase DDT degradation by $64 \%$ from $52 \%$ without rhamnolipid (Bhatt et al., 2021b). Studies on mixed consortia of Pleurotus ostreatus (white-rot fungus), Bacillus subtilis, and $P$. aeruginosa have produced biosurfactants that improve DDT biodegradation (Purnomo et al., 2017; Bhatt et al., 2021b). The hydrophobic herbicide 2,4,5-trichlorophenoxy acetic acid was degraded with the help of a biosurfactant produced from Pseudomonas cepacian (Abdul Salam and Das, 2013; Pang et al., 2020; Rawat et al., 2020). Similarly, introducing rhamnolipid to Rhodococcus species-D1 resulted in increased carbendazim biodegradation. The addition of rhamnolipid to the soil resulted in around $24-35 \%$ biodegradation of trifluralin (Bai et al., 2017). Under atrazine biodegradation, a marine strain of Bacillus velezensis MHNK1 produced surfactin lipopeptide. The atrazine was degraded entirely after using a combination of $B$. velezensis MHNK1 (2\%) and surfactin for 4 days (Jakinala et al., 2019).

A very interesting example of the application of biosurfactant in pesticide remediation is from the Patagonia region, which is famous for salmon farming, and to protect salmons from parasitic attack, cypermethrin (A pyrethroid category of pesticide) is used extensively in marine water. Scientists isolated microbial strains Rhodococcus species MS13, Rhodococcus species MS16, Pseudomonas species MS15a, and Pseudomonas species MS19 that could degrade cypermethrin by the production of biosurfactant (AguilaTorres et al., 2020). A novel strain of Serratia species Tan 611 has been isolated from Algeria's oil-contaminated wastewater. Its further sequencing and annotation revealed that it consists of genes that code for catechol 1,2-dioxygenase and naphthalene 1,2-dioxygenase, which are primarily responsible for aromatic derived hydrocarbon catabolism (Clements et al., 2019). An alkane degrading gene Lad-A that codes for monooxygenase have also been identified in the same strain. The bacterially produced biosurfactant has an emulsification index of about 43.47-65.22\% and forms biofilms in the presence of oil spills and petroleum. Further studies revealed that Serratia species strain Tan611 proves to be one of the best candidates in microbial remediation of aromatic pesticides (Semai et al., 2021). Biosurfactants boost the rate of pesticide degradation when a microbial consortium is used for bioremediation due to the synergistic influence of microbial communities (Purnomo et al., 2017; Bhatt et al., 2019; Femina Carolin et al., 2020).

\section{METAGENOMICS: UNRAVELING THE STRUCTURE AND COMPOSITION OF BIOSURFACTANT PRODUCING MICROBES AND THEIR ROLE IN PESTICIDE REMEDIATION}

Metagenomics analysis based on the sequence and function of the unculturable microbial community will help to uncover information in different ecological niches (Dubey et al., 2019; Kumar et al., 2019; Malla et al., 2019; Kumar and Dubey, 2020). The finding of novel microorganisms or their gene clusters expressing biosurfactants is an example of its application (Datta et al., 2020). Metagenomics provides access to the uncultured microbial population along with their taxonomic and functional composition based on targeted or shotgun sequencing of $16 \mathrm{~S}$ rRNA regions (Datta et al., 2020). The function-based approach detects and discovers genes capable of forming wholly new bioactive compounds that have never been identified before (Shikha et al., 2021). From pesticide-contaminated materials (soil, water), metagenomics helped create DNA libraries tested for biosurfactant-producing clones. There are many techniques for screening metagenomic libraries for biosurfactants, including function-based approaches like SIGEX (substrate-induced gene expression) and HTP (high-throughput) screening (Datta et al., 2020; Femina Carolin et al., 2020). The investigation of microbial metagenomes can also help researchers to gain a better knowledge of microbes that can produce biosurfactants in a variety of environments, particularly pesticides contaminated soils (Shikha et al., 2021).

The use of function-based metagenomic strategies can be a potent tool in helping to exploit the unique microbial diversity of pesticide-contaminated environments, thereby assisting in the ongoing search for novel biosurfactants with potentially important bioremediation applications (Yadav et al., 2019; Taş et al., 2021). Most research on biosurfactant producing microbes has been limited to soil isolates, primarily from the Pseudomonas and Bacillus species. However, with the help of metagenomics, it has recently been discovered that a diverse group of soil and marine microbes can produce biosurfactants (Dhanjal and Sharma, 2018; Guerra et al., 2018; Garg et al., 2021) and some of these biosurfactants have shown potential in bioremediation of pesticides (Kennedy et al., 2011; Ghosh and Das, 2018). These microbes include Azotobacter chroococcum, Cobelia species, Myroides species, Nocardiopsis alba MSA10, Alcanivorax species, Micrococcus luteus, Yarrowia lipolytica. There is a variety of screening approaches for detecting biosurfactant-producing microbes (as discussed in section "Methods for Detection of Microbial Biosurfactants"), some of which could be used for high-throughput (HTP) metagenomic library screening (Domingos et al., 2015; Dhanjal and Sharma, 2018; Guerra et al., 2018). Thus, in screening, it is likely that novel gene clusters involved in biosurfactant 


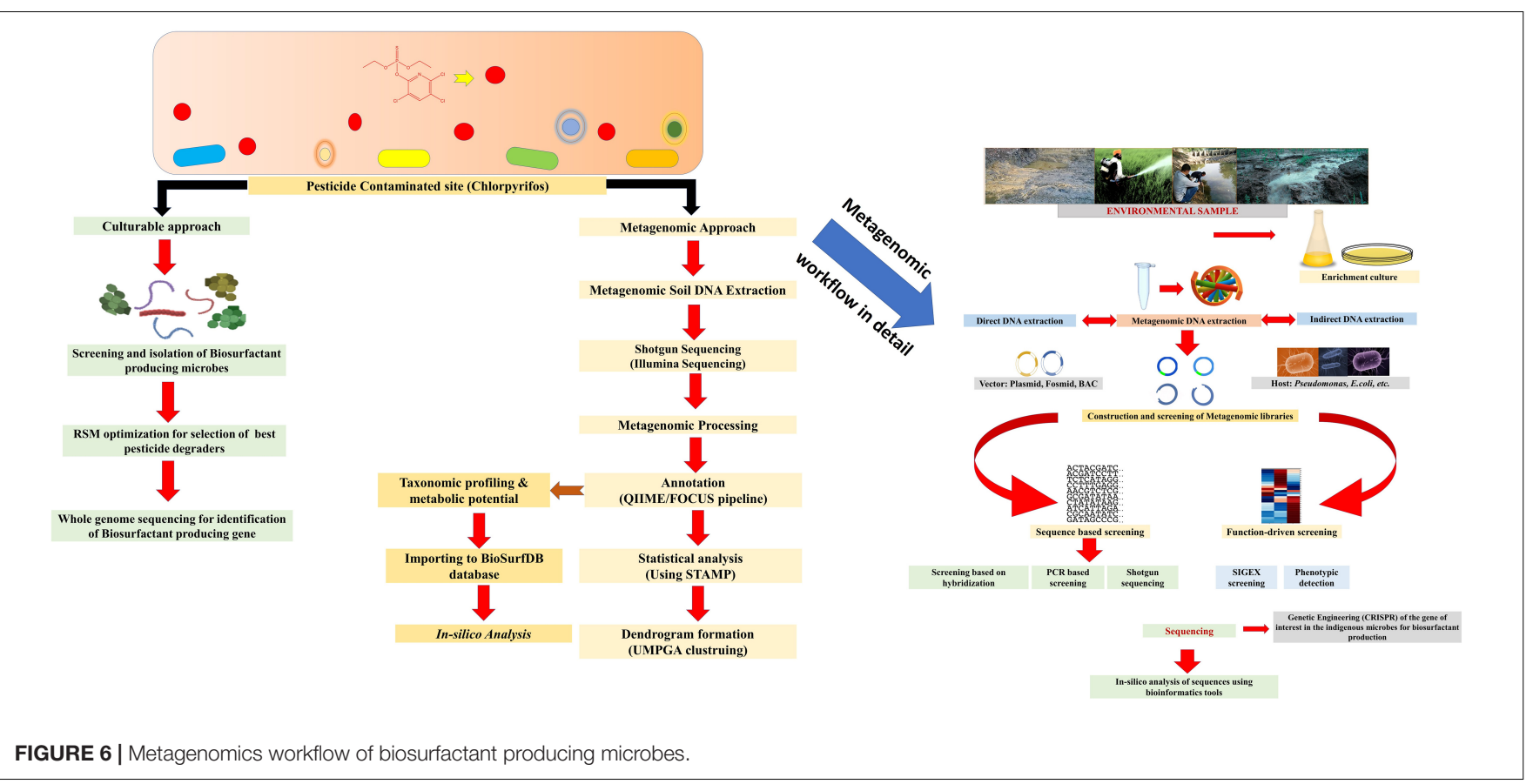

production from soil and aquatic microbial assemblages will be discovered, speeding up the development of bioremediation technologies involving biosurfactants in pesticide-contaminated environments (Hemmat-Jou et al., 2018; Taş et al., 2021). The whole workflow of metagenomics investigation of biosurfactant producing microbes is presented in Figure 6.

Metagenomics assists in the investigation of unique biosurfactant-producing genes from the bacteria present in diverse environments and distinct pathways and approaches for improved biosurfactant production. These investigations helped in finding two novel biosurfactants; palmitoyl putrescine and $\mathrm{N}$-acyl amino acids (Jackson et al., 2015; Williams and Trindade, 2017; Hu et al., 2019; Singh et al., 2020b). Given the amount and diversity of biosurfactant synthesizing microbes found in cultured isolates, it is believed that employing metagenomics to investigate the even larger uncultured component of the microbial community will lead to major novel biosurfactant discoveries (Datta et al., 2020; Singh et al., 2020b). A group of researchers identified a new gene involved in biosurfactant synthesis and helps in hydrocarbon degradation. They named it MBSP1 (Carla da Silva Araújo et al., 2020) (metagenomic biosurfactant protein 1) (Araújo et al., 2020). Thies et al. (2016) conducted a metagenomic study by collecting samples from the drain of the slaughterhouse that was rich in microbes belonging to flavobacteriaceae and, through NMR-spectroscopy identified novel biosurfactant as $\mathrm{N}$-acyltyrosines along with $\mathrm{N}$-myristoyl-tyrosine as the dominant species (Thies et al., 2016). Metagenomics delivers an adequate metagenomic database that will give a substantial stock of genes to develop novel microbial strains for targeted application in biosurfactant production and bioremediation (Malla et al., 2018; Datta et al., 2020; Douglas et al., 2020; Kumar et al., 2021b). Metagenomics coupled with bioinformatics removes all the obstacles faced in the process of genomic studies such as phylogenetic analysis, taxonomic profiling, molecular phylogeny, functional characterization of metagenomes, and enzymes and system biology studies, including genetic engineering through CRISPR or TALEN (Singh et al., 2020b). Quite a few bioinformatic pipelines have been developed (Table 2), such as QIIME (quantitative insights into microbial ecology), PICRUSt (phylogenetic investigation of communities by reconstruction of unobserved states), MG-RAST (metagenomic rapid annotations using subsystems technology), Mothur, CLARK, MetaPhlAn2 (metagenomic phylogenetic analysis), MICCA, Metaphyler, $\mathrm{MOCAT}_{2}$, TIPP2, mOTU $\mathrm{sv}_{2}$, Bracken, etc., for sequence classification and taxonomic profiling of metagenomic data (Liu et al., 2010; Albanese et al., 2015; Truong et al., 2015; Douglas et al., 2020; Singh et al., 2020b). Metagenomics coupled with in-silico bioinformatic tools or repositories such as KEGG (Kyoto encyclopedia of genes and genomes), COG (clusters of orthologous groups), EAWAG$\mathrm{BBD}$ pathway prediction system, enviPath, BIOWIN, etc., helps in predictive degradation of pesticides along with the metabolite/biosurfactant identification involved in degradation mechanism (Awasthi et al., 2020; Rodríguez et al., 2020; Shah et al., 2021; Singh et al., 2021). A repository named BioSurfDB (biosurfactant degradation database) consists of about 1,077 microbes, 3,763 genes, 3,430 proteins, and 47 detailed bioremediation pathways using biosurfactants (Araújo et al., 2020; Meenatchi et al., 2020; Kumari and Kumar, 2021).

To date, only a few research employing genetic modification methods for biosurfactant production have been published, and one such research is genetic modification of wild Bacillus strain for surfactin production (Tsuge et al., 2001). Bacillus species are engineered to increase their production through operon promoter transfer (SrfA) or upregulation of the exporter (YerP). Due to intricate metabolic regulation and its long 
TABLE 2 | Bioinformatic pipelines for metagenomic data analysis.

\begin{tabular}{ll}
\hline $\begin{array}{l}\text { Bioinformatic } \\
\text { pipeline }\end{array}$ & Description \\
\hline Squeeze MATA & $\begin{array}{l}\text { Squeeze Meta (A fully automated pipeline) provides multi-metagenome } \\
\text { assistance, which allows for the co-assembly of correlated metagenomes as } \\
\text { well as the retrieval of specific genomes via binning techniques. }\end{array}$ \\
ANASTASIA & $\begin{array}{l}\text { ANASTASIA (automated nucleotide amino-acid sequences translational } \\
\text { platform for systemic interpretation and analysis) offers a diverse set of } \\
\text { bioinformatics toolkits, both publicly available and proprietary, that can be } \\
\text { integrated into a variety of algorithmic analytic workflows to perform a variety of } \\
\text { data processing applications on (meta)genomic sequence data - sets. }\end{array}$
\end{tabular}

MetaWRAP

WebMGA

MetaSUB

MetAMOS

SmashCommunity

PALEOMIX

ARGs-OAP

HOME-BIO

QIIME

MICCA

RIEMS

MG-RAST

PICRUSt

MetaPhIAn

FMAP

TIPP2 comprehensive pipeline for metagenomics data analysis that consists of three distinct analytical modules that are meant to analyze big NGS datasets comprehensively.

QIIME is a microbial community analysis software program that has been used to examine and understand nucleic acid data sets from fungal, viral, bacterial, and archaeal populations.

MICCA is a software pipeline that rapidly integrates quality filtering, clustering of Operational Taxonomic Units (OTUs), taxonomic classification assignment, and phylogenetic tree inference for amplicon metagenomic datasets. It produces reliable findings while maintaining a reasonable balance of modularity and usability.

RIEMS, assigns every individual read sequence inside a dataset taxonomically by cascading different sequence analyses with decreasing stringency of the assignments utilizing multiple software tools. Following the completion of the analyses, the results are reported in a taxonomically ordered outcome procedure.

MG-RAST is a data platform for processing, analyzing, sharing, and distributing metagenomic datasets that accept open submissions.

PICRUSt predicts the functional potential of a bacterial community based on marker gene sequencing profiles.

MetaPhIAn (Metagenomic Phylogenetic Analysis) is a program that uses metagenomic shotgun sequencing data to profile the makeup of microbial communities. It depends on 17,000 reference genomes to identify unique clade-specific marker genes.

FMAP (Functional Mapping and Analysis Pipeline) is an open-sourced, stand-alone functional analysis pipeline for analyzing whole metagenomic and meta transcriptomic sequencing data.

It is a marker gene-based abundance profiling method that controls classification precision and recall by combining phylogenetic placement with statistical methodologies. Over the original TIPP technique, it includes an updated set of reference packages and various algorithmic advancements.
README.TIPP.md smirarab/sepp/blob/tipp2/
Link

https://github.com/

jtamames/SqueezeMeta

https://galaxyproject.org/ use/anastasia/

https://github.com/bxlab/ metaWRAP

http://weizhong-lab.ucsd. edu/webMGA/ (accessed December 02, 2021)

https://github.com/ MetaSUB/CAP2

https://github.com/ treangen/MetAMOS

http://www.bork.embl.de/ software/smash/

http://geogenetics.ku.dk publications/paleomix http://smile.hku.hk/SARGs

https://github.com/carlferr/ HOME-BIO

References

Tamames and

Puente-Sánchez, 2019

Koutsandreas et al., 2019

Uritskiy et al., 2018

Wu et al., 2011; Piumini

et al., 2021

Danko and Mason, 2020

Treangen et al., 2013;

Nathani et al., 2020

Arumugam et al., 2010; Sharma et al., 2021

Schubert et al., 2014

Yang et al., 2016

Ferravante et al., 2021

https://qiime2.org/

López-García et al., 2018

https://micca.readthedocs. io/en/latest/

https://github.com/EBI-

Scheuch et al., 2015

COMMUNITY/fli-RIEMS

https://www.mg-rast.org/

Keegan et al., 2016

https://github.com/picrust/

Douglas et al., 2020

picrust2

https://huttenhower.sph.

harvard.edu/metaphlan2/

Truong et al., 2015

https://github.com/

Kim et al., 2016

jiwoongbio/FMAP

https://github.com/

Shah et al., 2021 
genomic sequence, this operon's production is difficult ( $\mathrm{Hu}$ et al., 2019; Singh et al., 2020a). However, genetic engineering methods only resulted in a few or single-gene alterations, and commercial manufacturing of biosurfactants has yet to be achieved. As a result, experimentation-based optimizations to synthesize biosurfactants are still ongoing, and a new regulatory aspects need to be investigated, and the latest CRISPR based methods should be used to transfer biosurfactant producing genes to indigenous microbes residing in contaminated sites (Mulligan, 2009; Sekhon et al., 2011; Soares da Silva et al., 2019; Kumar and Dubey, 2020).

\section{CONCLUSION AND PROSPECTS}

Pesticides are complex compounds that are hydrophobic. When used in excess, pesticides pollute the air, soil, and water bodies because they interact with soil particles and leach deep into the soil and water bodies, making them inaccessible for microbial activity to thrive. Microbial biosurfactants serve an essential role in making these pesticides accessible for microbial enzymatic breakdown. Biosurfactants dissolve pesticides linked to soil particles and create emulsions at and above their CMC, thus increasing the bioavailability of the pesticide molecule in the soil. Different microbes secrete different categories of biosurfactants, each of which contributes more or less to enhancing the remediation process. More emphasis should be placed on improving process parameters to maximize the production of biosurfactants and their application in pesticide remediation. Tapping the potential of biosurfactant producing microbes by using the latest omics platform and gene-editing tools may offer a sustainable way to remediate these pesticides from the environment.

Although, research is going on for the production of biosurfactants from microbes. But still, many areas remain unexplored and need further investigation, such as:

- Most of the microbial biosurfactants have anti-microbial activities and are not suitable for remediation studies as this may harm the remediation process instead of enhancing it.

\section{REFERENCES}

Abbasi, H., Hamedi, M. M., Lotfabad, T. B., Zahiri, H. S., Sharafi, H., Masoomi, F., et al. (2012). Biosurfactant-producing bacterium, Pseudomonas aeruginosa MA01 isolated from spoiled apples: physicochemical and structural characteristics of isolated biosurfactant. J. Biosci. Bioeng. 113, 211-219. doi: 10.1016/j.jbiosc.2011.10.002

Abdul Salam, J., and Das, N. (2013). Enhanced biodegradation of lindane using oil-in-water bio-microemulsion stabilized by biosurfactant produced by a new yeast strain, Pseudozyma VITJzN01. J. Microbiol. Biotechnol. 23, 1598-1609. doi: 10.4014/jmb.1307.07016

Abouseoud, M., Maachi, R., Amrane, A., Boudergua, S., and Nabi, A. (2008). Evaluation of different carbon and nitrogen sources in production of biosurfactant by Pseudomonas fluorescens. Desalination 223, 143-151. doi: 10.1016/j.desal.2007.01.198
- Pesticide manufacturers must switch to biosurfactants instead of synthetic surfactants used as emulsifiers as they are highly toxic and persistent in the environment.

- Metagenomics coupled with DNA-stable isotope probing can be used in future studies to identify novel microbes with biosurfactant producing potential as it overcomes the impediment faced in functional screening using metagenomics.

- Metagenomics studies and other omics and In-silico studies need to enhance access to biosurfactants producing microbes from highly contaminated habitats or high-stress conditions such as high $\mathrm{pH}$, temperature, and salinity, etc.

- More genetic and bioengineering studies need to be conducted to identify genes involved in biosurfactant production and the implementation of advanced CRISPR (clustered regularly interspaced short palindromic repeats) technology to enhance biosurfactants' production.

- Identification of biosurfactant genes and their incorporation into microbial species commonly found in contaminated sites utilizing the CRISPR tool which will enhance the process of pesticide remediation.

\section{AUTHOR CONTRIBUTIONS}

AR prepared the draft of the manuscript under the supervision and guidance of AK. AK and JD revised and edited the manuscript. All authors contributed to the article and approved the submitted version.

\section{FUNDING}

AR received a Ph.D. fellowship from the host university. JD and AK acknowledges the research support provided by Rhodes University.

\section{ACKNOWLEDGMENTS}

AR would like to thank the University Ph.D. fellowship for supporting this study.

Adetunji, A. I., and Olaniran, A. O. (2021). Production and potential biotechnological applications of microbial surfactants: an overview. Saudi J. Biol. Sci. 28, 669-679. doi: 10.1016/J.SJBS.2020.10.058

Aguila-Torres, P., Maldonado, J., Gaete, A., Figueroa, J., González, A., Miranda, R., et al. (2020). Biochemical and genomic characterization of the cypermethrindegrading and biosurfactant-producing bacterial strains isolated from marine sediments of the Chilean Northern Patagonia. Mar. Drugs 18:252. doi: 10.3390/ md18050252

Akbari, S., Abdurahman, N. H., Yunus, R. M., Fayaz, F., and Alara, O. R. (2018). Biosurfactants-a new frontier for social and environmental safety: a mini review. Biotechnol. Res. Innov. 2, 81-90. doi: 10.1016/j.biori.2018.09.001

Al-Bahry, S. N., Al-Wahaibi, Y. M., Elshafie, A. E., Al-Bemani, A. S., Joshi, S. J., Al-Makhmari, H. S., et al. (2013). Biosurfactant production by Bacillus subtilis B20 using date molasses and its possible application in enhanced oil recovery. Int. Biodeterior. Biodegradation 81, 141-146. 
Albanese, D., Fontana, P., De Filippo, C., Cavalieri, D., and Donati, C. (2015). MICCA: a complete and accurate software for taxonomic profiling of metagenomic data. Sci. Rep. 5:9743. doi: 10.1038/srep09743

Alyousif, N., Al Luaibi, Y. Y., and Hussein, W. (2021). Distribution and molecular characterization of biosurfactant-producing bacteria. Biodivers. J. Biol. Divers. $21,4034-4040$.

Anand, N., Chakraborty, P., and Ray, S. (2021). Human exposure to organochlorine, pyrethroid and neonicotinoid pesticides: comparison between urban and semi-urban regions of India. Environ. Pollut. 270:116156. doi: 10. 1016/j.envpol.2020.116156

Araújo, W. J., Oliveira, J. S., Araújo, S. C. S., Minnicelli, C. F., Silva-Portela, R. C. B., da Fonseca, M. M. B., et al. (2020). Microbial culture in minimal medium with oil favors enrichment of biosurfactant producing genes. Front. Bioeng. Biotechnol. 8:962. doi: 10.3389/fbioe.2020.00962

Arisekar, U., Shakila, R. J., Jeyasekaran, G., Shalin, R., Kumar, P., Malani, A. H., et al. (2018). Accumulation of organochlorine pesticide residues in fish, water, and sediments in the Thamirabarani river system of southern peninsular India. Environ. Nanotechnol. Monit. Manag. 11:100194.

Arumugam, M., Harrington, E. D., Foerstner, K. U., Raes, J., and Bork, P. (2010). SmashCommunity: a metagenomic annotation and analysis tool. Bioinformatics 26, 2977-2978. doi: 10.1093/BIOINFORMATICS/BTQ536

Awasthi, M. K., Ravindran, B., Sarsaiya, S., Chen, H., Wainaina, S., Singh, E., et al. (2020). Metagenomics for taxonomy profiling: tools and approaches. Bioengineered 11, 356-374. doi: 10.1080/21655979.2020.1736238

Bages-Estopa, S., White, D. A., Winterburn, J. B., Webb, C., and Martin, P. J. (2018). Production and separation of a trehalolipid biosurfactant. Biochem. Eng. J. 139, 85-94. doi: $10.1111 /$ jam. 12287

Bai, N., Wang, S., Abuduaini, R., Zhang, M., Zhu, X., and Zhao, Y. (2017). Rhamnolipid-aided biodegradation of carbendazim by Rhodococcus sp. D1: characteristics, products, and phytotoxicity. Sci. Total Environ. 590-591, 343-351. doi: 10.1016/j.scitotenv.2017.03.025

Banat, I. M. (1995). Biosurfactants production and possible uses in microbial enhanced oil recovery and oil pollution remediation: a review. Bioresour. Technol. 51, 1-12. doi: 10.1016/0960-8524(94)00101-6

Banat, I. M., Franzetti, A., Gandolfi, I., Bestetti, G., Martinotti, M. G., Fracchia, L., et al. (2010). Microbial biosurfactants production, applications and future potential. Appl. Microbiol. Biotechnol. 87, 427-444. doi: 10.1007/s00253-0102589-0

Batista, S. B., Mounteer, A. H., Amorim, F. R., and Tótola, M. R. (2006). Isolation and characterization of biosurfactant/bioemulsifier-producing bacteria from petroleum contaminated sites. Bioresour. Technol. 97, 868-875. doi: 10.1016/ j.biortech.2005.04.020

Bhati, S., Kumar, V., Singh, S., and Singh, J. (2019). Synthesis, biological activities and docking studies of piperazine incorporated 1, 3, 4-oxadiazole derivatives. J. Mol. Struct. 1191, 197-205. doi: 10.1016/j.molstruc.2019.04.106

Bhatt, P., Gangola, S., Bhandari, G., Zhang, W., Maithani, D., Mishra, S., et al. (2021a). New insights into the degradation of synthetic pollutants in contaminated environments. Chemosphere 268:128827. doi: 10.1016/j. chemosphere.2020.128827

Bhatt, P., Verma, A., Gangola, S., Bhandari, G., and Chen, S. (2021b). Microbial glycoconjugates in organic pollutant bioremediation: recent advances and applications. Microb. Cell Fact. 20, 1-18. doi: 10.1186/s12934-021-01556-9

Bhatt, P., Gangola, S., Chaudhary, P., Khati, P., Kumar, G., Sharma, A., et al. (2019). Pesticide induced up-regulation of esterase and aldehyde dehydrogenase in indigenous Bacillus spp. Bioremediat. J. 23, 42-52. doi: 10.1080/10889868.2019. 1569586

Bonvoisin, T., Utyasheva, L., Knipe, D., Gunnell, D., and Eddleston, M. (2020). Suicide by pesticide poisoning in India: a review of pesticide regulations and their impact on suicide trends. BMC Public Health 20:251. doi: 10.1186/S12889020-8339-Z

Bordoloi, N. K., and Konwar, B. K. (2009). Bacterial biosurfactant in enhancing solubility and metabolism of petroleum hydrocarbons. J. Hazard. Mater. 170, 495-505.

Briceño, G., Lamilla, C., Leiva, B., Levio, M., Donoso-Piñol, P., Schalchli, H., et al. (2020). Pesticide-tolerant bacteria isolated from a biopurification system to remove commonly used pesticides to protect water resources. PLoS One 15:e234865. doi: 10.1371/journal.pone.0234865
Bustamante, M., Durán, N., and Diez, M. C. (2012). Biosurfactants are useful tools for the bioremediation of contaminated soil: a review. J. Soil Sci. Plant Nutr. 12, 667-687. doi: 10.4067/s0718-95162012005000024

Carla da Silva Araújo, S., Silva-portela, R. C. B., Chaves de Lima, D., Maria Bernardes da fonsêca, M., Araújo, W. J., Bezerra da Silva, U., et al. (2020). MBSP1: a biosurfactant protein derived from a metagenomic library with activity in oil degradation. Sci. Rep. 10:1340. doi: 10.1038/s41598-020-58330-x

Casullo De Araújo, H. W., Fukushima, K., and Campos Takaki, G. M. (2010). Prodigiosin production by Serratia marcescens UCP 1549 using renewableresources as a low cost substrate. Molecules 15, 6931-6940. doi: 10.3390/ molecules 15106931

Chaprão, M. J., Ferreira, I. N., Correa, P. F., Rufino, R. D., Luna, J. M., Silva, E. J., et al. (2015). Application of bacterial and yeast biosurfactants for enhanced removal and biodegradation of motor oil from contaminated sand. Electron. J. Biotechnol. 18, 471-479.

Chong, H., and Li, Q. (2017). Microbial production of rhamnolipids: opportunities, challenges and strategies. Microb. Cell Fact. 16:137. doi: 10.1186/s12934-0170753-2

Clements, T., Ndlovu, T., Khan, S., and Khan, W. (2019). Biosurfactants produced by Serratia species: classification, biosynthesis, production and application. Appl. Microbiol. Biotechnol. 103, 589-602. doi: 10.1007/s00253-018-9520-5

Cooper, D. G., and Goldenberg, B. G. (1987). Surface-active agents from two Bacillus species. Appl. Environ. Microbiol. 53, 224-229. doi: 10.1128/AEM.53.2. 224-229.1987

Cortés-Camargo, S., Pérez-Rodríguez, N., Oliveira, R. P., de, S., Huerta, B. E. B., and Domínguez, J. M. (2016). Production of biosurfactants from vine-trimming shoots using the halotolerant strain Bacillus tequilensis ZSB10. Ind. Crops Prod. 79, 258-266. doi: 10.1016/j.indcrop.2015.11.003

Da Rocha, U. N., Andreote, F. D., de Azevedo, J. L., van Elsas, J. D., and van Overbeek, L. S. (2010). Cultivation of hitherto-uncultured bacteria belonging to the Verrucomicrobia subdivision 1 from the potato (Solanum tuberosum L.) rhizosphere. J. Soils Sediments 10, 326-339. doi: 10.1007/s11368-009-0160-3

Damalas, C. A., and Eleftherohorinos, I. G. (2011). Pesticide exposure, safety issues, and risk assessment indicators. Int. J. Environ. Res. Public Health 8, 1402-1419. doi: 10.3390/ijerph8051402

Danko, D. C., and Mason, C. (2020). The MetaSUB microbiome core analysis pipeline enables large scale metagenomic analysis. arXiv [Preprint] Available online at: http://arxiv.org/abs/2009.12338 (accessed October 26, 2021),

Das, A. J., and Kumar, R. (2018). Utilization of agro-industrial waste for biosurfactant production under submerged fermentation and its application in oil recovery from sand matrix. Bioresour. Technol. 260, 233-240. doi: 10.1016/ j.biortech.2018.03.093

Datta, S., Rajnish, K. N., Samuel, M. S., Pugazlendhi, A., and Selvarajan, E. (2020). Metagenomic applications in microbial diversity, bioremediation, pollution monitoring, enzyme and drug discovery. A review. Environ. Chem. Lett. 18, 1229-1241. doi: 10.1007/s10311-020-01010-z

Davies, W. P. (2003). An historical perspective from the green revolution to the gene revolution. Nutr. Rev. 61(Suppl. 6), S124-S134. doi: 10.1301/nr.2003.jun. S124-S134

Dayamrita, K. K., Divya, K. K., Sreelakshmi, R., Arjun, E. J., and John, F. (2020). Isolation and characterization of hydrocarbon degrading bacteria from oil contaminated soil-potential for biosurfactant assisted bioremediation. AIP Conf. Proc. 2263:020009. doi: 10.1063/5.0017395

de Andrade, C. J., de Andrade, L. M., Bution, M. L., Dolder, M. A. H., Barros, F. F. C., and Pastore, G. M. (2016). Optimizing alternative substrate for simultaneous production of surfactin and 2, 3-butanediol by Bacillus subtilis LB5a. Biocatal. Agric. Biotechnol. 6, 209-218.

De Giani, A., Zampolli, J., and Di Gennaro, P. (2021). Recent trends on biosurfactants with antimicrobial activity produced by bacteria associated with human health: different perspectives on their properties, challenges, and potential applications. Front. Microbiol. 12:678. doi: 10.3389/fmicb.2021. 655150

de Oliveira Schmidt, V. K., de Souza Carvalho, J., de Oliveira, D., and de Andrade, C. J. (2021). Biosurfactant inducers for enhanced production of surfactin and rhamnolipids: an overview. World J. Microbiol. Biotechnol. 37, 1-15. doi: 10. 1007/s11274-020-02970-8 
Dhanjal, D. S., and Sharma, D. (2018). "Microbial metagenomics for industrial and environmental bioprospecting: the unknown envoy," in Microbial Bioprospecting for Sustainable Development, eds J. Singh, D. Sharma, G. Kumar, and N. Sharma (Singapore: Springer), 327-352.

Domingos, D. F., de Faria, A. F., de Souza Galaverna, R., Eberlin, M. N., Greenfield, P., Zucchi, T. D., et al. (2015). Genomic and chemical insights into biosurfactant production by the mangrove-derived strain Bacillus safensis CCMA-560. Appl. Microbiol. Biotechnol. 99, 3155-3167. doi: 10.1007/s00253-015-6377-8

Domínguez Rivera, Á, Martínez Urbina, M. Á, and López y López, V. E. (2019). Advances on research in the use of agro-industrial waste in biosurfactant production. World J. Microbiol. Biotechnol. 35:155. doi: 10.1007/s11274-0192729-3

Dos Santos, J. J., and Maranho, L. T. (2018). Rhizospheric microorganisms as a solution for the recovery of soils contaminated by petroleum: a review. J. Environ. Manag. 210, 104-113. doi: 10.1016/j.jenvman.2018.01.015

Douglas, G. M., Maffei, V. J., Zaneveld, J. R., Yurgel, S. N., Brown, J. R., Taylor, C. M., et al. (2020). PICRUSt2 for prediction of metagenome functions. Nat. Biotechnol. 38, 685-688.

Dubey, A., Malla, M. A., Khan, F., Chowdhary, K., Yadav, S., Kumar, A., et al. (2019). Soil microbiome: a key player for conservation of soil health under changing climate. Biodivers. Conserv. 28, 2405-2429. doi: 10.1007/s10531-01901760-5

Dusane, D. H., Nancharaiah, Y. V., Zinjarde, S. S., and Venugopalan, V. P. (2010). Rhamnolipid mediated disruption of marine Bacillus pumilus biofilms. Colloids Surf. B Biointerfaces 81, 242-248. doi: 10.1016/J.COLSURFB.2010.07. 013

Enaime, G., Nettmann, E., Berzio, S., Baçaoui, A., Yaacoubi, A., Wichern, M., et al. (2019). Performance and microbial analysis during long-term anaerobic digestion of olive mill wastewater in a packed-bed biofilm reactor. J. Chem. Technol. Biotechnol. 95, 850-861. doi: 10.1002/jctb.6275

FAOSTAT (2021). FAOSTAT. Available online at: https://www.fao.org/faostat/en/ \#home (accessed September 15, 2021).

Femina Carolin, C., Senthil Kumar, P., Janet Joshiba, G., Ramamurthy, R., and Varjani, S. J. (2020). Bioremediation of 2,4-diaminotoluene in aqueous solution enhanced by lipopeptide biosurfactant production from bacterial strains. J. Environ. Eng. 146:04020069. doi: 10.1061/(asce)ee.1943-7870.0001740

Fenibo, E. O., Ijoma, G. N., Selvarajan, R., and Chikere, C. B. (2019). Microbial surfactants: the next generation multifunctional biomolecules for applications in the petroleum industry and its associated environmental remediation. Microorganisms 7:581. doi: 10.3390/microorganisms7110581

Ferravante, C., Memoli, D., Palumbo, D., Ciaramella, P., Di Loria, A., D’Agostino, Y., et al. (2021). HOME-BIO (sHOtgun MEtagenomic analysis of BIOlogical entities): a specific and comprehensive pipeline for metagenomic shotgun sequencing data analysis. BMC Bioinformatics 22(Suppl. 7):106. doi: 10.1186/ S12859-021-04004-Y

Foong, S. Y., Ma, N. L., Lam, S. S., Peng, W., Low, F., Lee, B. H., et al. (2020). A recent global review of hazardous chlorpyrifos pesticide in fruit and vegetables: prevalence, remediation and actions needed. J. Hazard. Mater. 400:123006. doi: 10.1016/j.jhazmat.2020.123006

García-Reyes, S., Yáñez-Ocampo, G., Wong-Villarreal, A., Rajaretinam, R. K., Thavasimuthu, C., Patiño, R., et al. (2018). Partial characterization of a biosurfactant extracted from Pseudomonas sp. B0406 that enhances the solubility of pesticides. Environ. Technol. 39, 2622-2631. doi: 10.1080/ 21622515.2017.1363295

Garg, N., Bhattacherjee, A. K., Shukla, P. K., and Singh, B. (2021). Influence of imidacloprid on bacterial community diversity of mango orchard soil assessed through 16S rRNA sequencing-based metagenomic analysis. Environ. Monit. Assess. 193:102. doi: 10.1007/S10661-021-08885-7

Gaur, V. K., Bajaj, A., Regar, R. K., Kamthan, M., Jha, R. R., Srivastava, J. K., et al. (2019). Rhamnolipid from a Lysinibacillus sphaericus strain IITR51 and its potential application for dissolution of hydrophobic pesticides. Bioresour. Technol. 272, 19-25. doi: 10.1016/j.biortech.2018.09.144

Geetha, S. J., Banat, I. M., and Joshi, S. J. (2018). Biosurfactants: production and potential applications in microbial enhanced oil recovery (MEOR). Biocatal. Agric. Biotechnol. 14, 23-32. doi: 10.1016/j.bcab.2018.01.010

Gennari, M., Messina, C., Abbate, C., Baglieri, A., and Boursier, C. (2009). Solubility and adsorption behaviors of chlorpyriphos-methyl in the presence of surfactants. J. Environ. Sci. Health. B 44, 235-240. doi: 10.1080/ 03601230902728211

Ghosh, S., and Das, A. P. (2018). Metagenomic insights into the microbial diversity in manganese-contaminated mine tailings and their role in biogeochemical cycling of manganese. Sci. Rep. 8:8257. doi: 10.1038/s41598-018-26311-w

Giri, B. S., Geed, S., Vikrant, K., Lee, S. S., Kim, K. H., Kumar Kailasa, S., et al. (2020). Progress in bioremediation of pesticide residues in the environment. Environ. Eng. Res. 26:200446. doi: 10.4491/eer.2020.446

GOI (2021). Statistical Database | Directorate of Plant Protection, Quarantine \& Storage. Available online at: http://ppqs.gov.in/statistical-database (accessed September 15, 2021).

Guerra, A. B., Oliveira, J. S., Silva-Portela, R. C., Araújo, W., Carlos, A. C., Vasconcelos, A. T. R., et al. (2018). Metagenome enrichment approach used for selection of oil-degrading bacteria consortia for drill cutting residue bioremediation. Environ. Pollut. 235, 869-880. doi: 10.1016/j.envpol.2018.01. 014

Gunnell, D., and Eddleston, M. (2003). Suicide by intentional ingestion of pesticides: a continuing tragedy in developing countries. Int. J. Epidemiol. 32, 902-909. doi: 10.1093/ije/dyg307

Hasanizadeh, P., Moghimi, H., and Hamedi, J. (2017). Biosurfactant production by Mucor circinelloides on waste frying oil and possible uses in crude oil remediation. Water Sci. Technol. 76, 1706-1714. doi: 10.2166/wst.2017.338

Hazra, C., Kundu, D., Ghosh, P., Joshi, S., Dandi, N., and Chaudhari, A. (2011). Screening and identification of Pseudomonas aeruginosa AB4 for improved production, characterization and application of a glycolipid biosurfactant using low-cost agro-based raw materials. J. Chem. Technol. Biotechnol. 86, 185-198. doi: $10.1002 /$ jctb. 2480

Hemmat-Jou, M. H., Safari-Sinegani, A. A., Mirzaie-Asl, A., and Tahmourespour, A. (2018). Analysis of microbial communities in heavy metals-contaminated soils using the metagenomic approach. Ecotoxicology 27, 1281-1291. doi: 10. 1007/S10646-018-1981-X

Hippolyte, M. T., Augustin, M., Hervé, T. M., Robert, N., and Devappa, S. (2018). Application of response surface methodology to improve the production of antimicrobial biosurfactants by Lactobacillus paracasei subsp. Tolerans n 2 using sugar cane molasses as substrate. Bioresour. Bioprocess. 5:48. doi: 10.1186/ s40643-018-0234-4

Hobbs, R. J., Higgs, E., and Harris, J. A. (2009). Novel ecosystems: implications for conservation and restoration. Trends Ecol. Evol. 24, 599-605.

Hu, F., Liu, Y., and Li, S. (2019). Rational strain improvement for surfactin production: enhancing the yield and generating novel structures. Microb. Cell Fact. 18, 42. doi: 10.1186/S12934-019-1089-X

Inakollu, S., Hung, H. C., and Shreve, G. S. (2004). Biosurfactant enhancement of microbial degradation of various structural classes of hydrocarbon in mixed waste systems. Environ. Eng. Sci. 21, 463-469. doi: 10.1089/1092875041358467

Ismail, H. Y., Isa, T., Ngoshe, I. Y., and Gajere, H. M. (2018). Biosurfactant production by bacteria isolated from hydrocarbon-impacted soil. Bioremediat. Sci. Technol. Res. 6, 1-4. doi: 10.21608/ejm.2011.260

Jackson, S. A., Borchert, E., O'Gara, F., and Dobson, A. D. (2015). Metagenomics for the discovery of novel biosurfactants of environmental interest from marine ecosystems. Curr. Opin. Biotechnol. 33, 176-182. doi: 10.1016/j.copbio.2015.03.004

Jain, D. K., Collins-Thompson, D. L., Lee, H., and Trevors, J. T. (1991). A dropcollapsing test for screening surfactant-producing microorganisms. J. Microbiol. Methods 13, 271-279. doi: 10.1016/0167-7012(91)90064-w

Jakinala, P., Lingampally, N., Kyama, A., and Hameeda, B. (2019). Enhancement of atrazine biodegradation by marine isolate Bacillus velezensis MHNK1 in presence of surfactin lipopeptide. Ecotoxicol. Environ. Saf. 182:109372. doi: 10.1016/j.ecoenv.2019.109372

Janek, T., Gudiña, E. J., Połomska, X., Biniarz, P., Jama, D., Rodrigues, L. R., et al. (2021). Sustainable surfactin production by Bacillus subtilis using crude glycerol from different wastes. Molecules 26:3488. doi: 10.3390/molecules26123488

Javee, A., Karuppan, R., and Subramani, N. (2020). Bioactive glycolipid biosurfactant from seaweed Sargassum myriocystum associated bacteria Streptomyces sp. SNJASM6. Biocatal. Agric. Biotechnol. 23:101505. doi: 10.1016/ j.bcab.2020.101505

Jezierska, S., Claus, S., Ledesma-Amaro, R., and Van Bogaert, I. (2019). Redirecting the lipid metabolism of the yeast Starmerella bombicola from glycolipid to fatty 
acid production. J. Ind. Microbiol. Biotechnol. 46, 1697-1706. doi: 10.1007/ s10295-019-02234- $x$

Jimoh, A. A., and Lin, J. (2019b). Enhancement of Paenibacillus sp. D9 lipopeptide biosurfactant production through the optimization of medium composition and its application for biodegradation of hydrophobic pollutants. Appl. Biochem. Biotechnol. 187, 724-743. doi: 10.1007/s12010-018-2847-7

Jimoh, A. A., and Lin, J. (2019a). Biosurfactant: a new frontier for greener technology and environmental sustainability. Ecotoxicol. Environ. Saf. 184:109607. doi: 10.1016/j.ecoenv.2019.109607

John, E. M., and Shaike, J. M. (2015). Chlorpyrifos: pollution and remediation. Environ. Chem. Lett. 13, 269-291. doi: 10.1007/s10311-015-0513-7

Kalyani, N., Goel, S., and Jaiswal, S. (2021). On-site sensing of pesticides using point-of-care biosensors: a review. Environ. Chem. Lett. 19, 345-354. doi: 10.1007/s10311-020-01070-1

Kannuri, N. K., and Jadhav, S. (2018). Generating toxic landscapes: impact on well-being of cotton farmers in Telangana, India. Anthropol. Med. 25, 121-140. doi: 10.1080/13648470.2017.1317398

Kapoor, D., Singh, S., Kumar, V., Romero, R., Prasad, R., and Singh, J. (2019). Antioxidant enzymes regulation in plants in reference to reactive oxygen species (ROS) and reactive nitrogen species (RNS). Plant Gene 19:100182.

Kaskatepe, B., and Yildiz, S. (2016). Rhamnolipid biosurfactants produced by pseudomonas species. Braz. Arch. Biol. Technol. 59, 1-16. doi: 10.1590/16784324-2016160786

Keegan, K. P., Glass, E. M., and Meyer, F. (2016). "MG-RAST, a metagenomics service for analysis of microbial community structure and function," in Microbial Environmental Genomics (MEG), eds F. Martin and S. Uroz (New York, NY: Springer)

Kennedy, J., O’Leary, N. D., Kiran, G. S., Morrissey, J. P., O'Gara, F., Selvin, J., et al. (2011). Functional metagenomic strategies for the discovery of novel enzymes and biosurfactants with biotechnological applications from marine ecosystems. J. Appl. Microbiol. 111, 787-799. doi: 10.1111/J.1365-2672.2011.05106.X

Khanna, S., and Pattnaik, P. (2019). Production and functional characterization of food compatible biosurfactants. Appl. Food Sci. J. 3, 1-4.

Kim, J., Kim, M. S., Koh, A. Y., Xie, Y., and Zhan, X. (2016). FMAP: functional mapping and analysis pipeline for metagenomics and metatranscriptomics studies. BMC Bioinformatics 17:420. doi: 10.1186/S12859-016-1278-0

Kosaric, N., Gray, N. C. C., and Cairns, W. L (eds) (2018). "Introduction: biotechnology and the surfactant industry," in Biosurfactants and Biotechnology, (Boca Raton, FL: Routledge), 1-19. doi: 10.1201/9781315138428

Koutsandreas, T., Ladoukakis, E., Pilalis, E., Zarafeta, D., Kolisis, F. N., Skretas, G., et al. (2019). ANASTASIA: an automated metagenomic analysis pipeline for novel enzyme discovery exploiting next generation sequencing data. Front. Genet. 10:469. doi: 10.3389/FGENE.2019.00469

Kumar, A., and Dubey, A. (2020). Rhizosphere microbiome: engineering bacterial competitiveness for enhancing crop production. J. Adv. Res. 24, 337-352. doi: 10.1016/j.jare.2020.04.014

Kumar, A., Singh, S. K., Kant, C., Verma, H., Kumar, D., Singh, P. P., et al. (2021a). Microbial biosurfactant: a new frontier for sustainable agriculture and pharmaceutical industries. Antioxidants 10:1472. doi: 10.3390/antiox10091472

Kumar, A., Dubey, A., Malla, M. A., and Dames, J. (2021b). Pyrosequencing and phenotypic microarray to decipher bacterial community variation in Sorghum bicolor (L.) Moench rhizosphere. Curr. Res. Microb. Sci. 2, 100025. doi: 10.1016/ j.crmicr.2021.100025

Kumar, A., Vyas, P., Malla, M. A., and Dubey, A. (2019). Taxonomic and functional annotation of termite degraded Butea monosperma (Lam.) Kuntze (Flame of the Forest). Open Microbiol. J. 13, 154-163. doi: 10.2174/ 1874285801913010154

Kumar, S., Kaushik, G., and Villarreal-Chiu, J. F. (2016). Scenario of organophosphate pollution and toxicity in India: a review. Environ. Sci. Pollut. Res. 23, 9480-9491. doi: 10.1007/S11356-016-6294-0

Kumari, P., and Kumar, Y. (2021). "Bioinformatics and computational tools in bioremediation and biodegradation of environmental pollutants," in Bioremediation for Environmental Sustainability, eds G. Saxena, V. Kumar, and M. Shah (Amsterdam: Elsevier), 421-444.

Lamilla, C., Schalchli, H., Briceño, G., Leiva, B., Donoso-Piñol, P., Barrientos, L., et al. (2021). A pesticide biopurification system: a source of biosurfactantproducing bacteria with environmental biotechnology applications. Agronomy 11:624. doi: 10.3390/agronomy11040624
Lai, C. C., Huang, Y. C., Wei, Y. H., and Chang, J. S. (2009). Biosurfactantenhanced removal of total petroleum hydrocarbons from contaminated soil. J. Hazard. Mater. 167, 609-614.

Lee, D. W., Lee, H., Kwon, B. O., Khim, J. S., Yim, U. H., Kim, B. S., et al. (2018). Biosurfactant-assisted bioremediation of crude oil by indigenous bacteria isolated from Taean beach sediment. Environ. Pollut. 241, 254-264. doi: 10. 1016/j.envpol.2018.05.070

Li, J., Deng, M., Wang, Y., and Chen, W. (2016). Production and characteristics of biosurfactant produced by Bacillus pseudomycoides BS6 utilizing soybean oil waste. Int. Biodeterior. Biodegradation 112, 72-79.

Lima, T. M., Procópio, L. C., Brandao, F. D., Carvalho, A. M., Tótola, M. R., and Borges, A. C. (2011). Biodegradability of bacterial surfactants. Biodegradation 22, 585-592.

Liu, B., Gibbons, T., Ghodsi, M., and Pop, M. (2010). "MetaPhyler: taxonomic profiling for metagenomic sequences," in Proceedings of the 2010 IEEE International Conference on Bioinformatics and Biomedicine (BIBM), Hong Kong, 95-100.

López-García, A., Pineda-Quiroga, C., Atxaerandio, R., Pérez, A., Hernández, I., García-Rodríguez, A., et al. (2018). Comparison of mothur and QIIME for the analysis of rumen microbiota composition based on 16S rRNA amplicon sequences. Front. Microbiol. 9:3010. doi: 10.3389/FMICB.2018.03010/FULL

Luna, J. M., Rufino, R. D., Sarubbo, L. A., and Campos-Takaki, G. M. (2013). Characterisation, surface properties and biological activity of a biosurfactant produced from industrial waste by Candida sphaerica UCP0995 for application in the petroleum industry. Colloids Surf. B Biointerf. 102, 202-209. doi: 10.1016/ j.colsurfb.2012.08.008

Maczek, J., Junne, S., and Götz, P. (2007). "Examining biosurfactant producing bacteria-an example for an automated search for natural compounds," in Application Note, (Jena: CyBio AG).

Madamwar, D., Tsuda, M., Solyanikova, I., Chen, S., Mishra, S., Lin, Z., et al. (2021). Recent advanced technologies for the characterization of xenobiotic-degrading microorganisms and microbial communities. Front. Bioeng. Biotechnol. 9:632059. doi: 10.3389/fbioe.2021.632059

Maia, M., Capão, A., and Procópio, L. (2019). Biosurfactant produced by oildegrading Pseudomonas putida AM-b1 strain with potential for microbial enhanced oil recovery. Bioremediat. J. 23, 302-310. doi: 10.1080/10889868. 2019.1669527

Malla, M. A., Dubey, A., Kumar, A., Yadav, S., Hashem, A., and Abd Allah, E. F. (2019). Exploring the human microbiome: the potential future role of nextgeneration sequencing in disease diagnosis and treatment. Front. Immunol. 9:2868. doi: 10.3389/fimmu.2018.02868

Malla, M. A., Dubey, A., Yadav, S., Kumar, A., Hashem, A., and Abd-Allah, E. F. (2018). Understanding and designing the strategies for the microbe-mediated remediation of environmental contaminants using omics approaches. Front. Microbiol. 9:1132. doi: 10.3389/fmicb.2018.01132

Manickam, N., Bajaj, A., Saini, H. S., and Shanker, R. (2012). Surfactant mediated enhanced biodegradation of hexachlorocyclohexane $(\mathrm{HCH})$ isomers by Sphingomonas sp. NM05. Biodegradation 23, 673-682. doi: 10.1007/s10532012-9543-z

Mansouri, A., Cregut, M., Abbes, C., Durand, M. J., Landoulsi, A., and Thouand, G. (2017). The environmental issues of DDT pollution and bioremediation: a multidisciplinary review. Appl. Biochem. Biotechnol. 181, 309-339. doi: 10. 1007/s12010-016-2214-5

Marcelino, P. R. F., Peres, G. F. D., Terán-Hilares, R., Pagnocca, F. C., Rosa, C. A., Lacerda, T. M., et al. (2019). Biosurfactants production by yeasts using sugarcane bagasse hemicellulosic hydrolysate as new sustainable alternative for lignocellulosic biorefineries. Ind. Crops Prod. 129, 212-223. doi: 10.1016/j. indcrop.2018.12.001

Meena, K. R., Dhiman, R., Singh, K., Kumar, S., Sharma, A., Kanwar, S. S., et al. (2021). Purification and identification of a surfactin biosurfactant and engine oil degradation by Bacillus velezensis KLP2016. Microb. Cell Factor. 20, 1-12. doi: 10.1186/s12934-021-01519-0

Meenatchi, R., Brindangnanam, P., Hassan, S., Rathna, K., Kiran, G. S., and Selvin, J. (2020). Diversity of a bacterial community associated with Cliona lobata Hancock and Gelliodes pumila (Lendenfeld, 1887) sponges on the South-East coast of India. Sci. Rep. 10:1558. doi: 10.1038/s41598-020-67717-9

Messner, P., Schaeffer, C., and Kosma, P. (2013). Bacterial cell-envelope glycoconjugates. Adv. Carbohydr. Chem. Biochem. 69, 209-272. 
Mishra, J., Dutta, V., and Arora, N. K. (2020). Biopesticides in India: technology and sustainability linkages. 3 Biotech 10:210. doi: 10.1007/S13205-020-02192-7

Mnif, I., and Ghribi, D. (2016). Glycolipid biosurfactants: main properties and potential applications in agriculture and food industry. J. Sci. Food Agric. 96, 4310-4320. doi: 10.1002/JSFA.7759

Moya Ramírez, I., Tsaousi, K., Rudden, M., Marchant, R., Jurado Alameda, E., García Román, M., et al. (2015). Rhamnolipid and surfactin production from olive oil mill waste as sole carbon source. Bioresour. Technol. 198, 231-236. doi: 10.1016/j.biortech.2015.09.012

Mulligan, C. N. (2009). Recent advances in the environmental applications of biosurfactants. Curr. Opin. Colloid Interf. Sci. 14, 372-378. doi: 10.1016/j.cocis. 2009.06.005

Nair, A. M., Rebello, S., Rishad, K. S., Asok, A. K., and Jisha, M. S. (2015). Biosurfactant facilitated biodegradation of quinalphos at high concentrations by Pseudomonas aeruginosa Q10. Soil Sedim. Contam. 24, 542-553. doi: 10. 1080/15320383.2015.988205

Narenderan, S. T., Meyyanathan, S. N., and Babu, B. (2020). Review of pesticide residue analysis in fruits and vegetables. Pre-treatment, extraction and detection techniques. Food Res. Int. 133:109141. doi: 10.1016/j.foodres.2020.109141

Nathani, N. M., Rajyaguru, R. H., Prashanth, P., Mootapally, C., and Dave, B. P. (2020). "Microbial omics: role in ecological studies and environmental control measures," in Environmental Biotechnology, Vol. 2, eds K. Gothandam, S. Ranjan, N. Dasgupta, and E. Lichtfouse (Cham: Springer), 173-196. doi: 10. 1007/978-3-030-38196-7_8

Nayak, S., Sahoo, A., Kolanthasamy, E., and Rao, K. (2020). "Role of pesticide application in environmental degradation and its remediation strategies," in Environmental Degradation: Causes and Remediation Strategies, Vol. 1, eds V. Kumar, J. Singh, and P. Kumar (Haridwar: Agriculture and Environmental Science Academy), 36 doi: 10.26832/aesa-2020-edcrs- 03

Nayarisseri, A., Singh, P., and Singh, S. K. (2019). Screening, isolation and characterization of biosurfactant-producing Bacillus tequilensis strain ANSKLAB04 from brackish river water. Int. J. Environ. Sci. Technol. 16, 7103-7112. doi: 10.1007/S13762-018-2089-9

Nitschke, M., and Pastore, G. M. (2006). Production and properties of a surfactant obtained from Bacillus subtilis grown on cassava wastewater. Bioresour. Technol. 97, 336-341. doi: 10.1016/j.biortech.2005.02.044

Niu, Y., Wu, J., Wang, W., and Chen, Q. (2019). Production and characterization of a new glycolipid, mannosylerythritol lipid, from waste cooking oil biotransformation by Pseudozyma aphidis ZJUDM34. Food Sci Nutr. 7, 937948. doi: $10.1002 /$ fsn 3.880

Odukkathil, G., and Vasudevan, N. (2016). Residues of endosulfan in surface and subsurface agricultural soil and its bioremediation. J. Environ. Manage. 165, 72-80. doi: 10.1016/j.jenvman.2015.09.020

Olasanmi, I. O., and Thring, R. W. (2018). The role of biosurfactants in the continued drive for environmental sustainability. Sustainability 10:4817. doi: $10.3390 /$ su10124817

Onaizi, S. A. (2018). Dynamic surface tension and adsorption mechanism of surfactin biosurfactant at the air-water interface. Eur. Biophys. J. 47, 631-640. doi: $10.1007 / \mathrm{s} 00249-018-1289-\mathrm{z}$

Onbasli, D., and Aslim, B. (2009). Effects of some organic pollutants on the exopolysaccharides (EPSs) produced by some Pseudomonas spp. strains. J. Hazard. Mater. 168, 64-67. doi: 10.1016/j.jhazmat.2009.01.131

Pacwa-Płociniczak, M., Płaza, G. A., Piotrowska-Seget, Z., and Cameotra, S. S. (2011). Environmental applications of biosurfactants: recent advances. Int. J. Mol. Sci. 12, 633-654. doi: 10.3390/ijms12010633

Pang, S., Lin, Z., Zhang, W., Mishra, S., Bhatt, P., and Chen, S. (2020). Insights into the microbial degradation and biochemical mechanisms of neonicotinoids. Front. Microbiol. 11:868. doi: 10.3389/fmicb.2020.00868

Panjiar, N., Sachan, S. G., and Sachan, A. (2017). Biosurfactants: a multifunctional microbial metabolite. Microb. Appl. 2, 213-229. doi: 10.1007/978-3-31952669-0_12

Parks, C. G., Hofmann, J. N., Beane Freeman, L. E., and Sandler, D. P. (2021). Agricultural pesticides and shingles risk in a prospective cohort of licensed pesticide applicators. Environ. Health Perspect. 129:077005. doi: 10.1289/ EHP7797

Patowary, K., Patowary, R., Kalita, M. C., and Deka, S. (2017). Characterization of biosurfactant produced during degradation of hydrocarbons using crude oil as sole source of carbon. Front. Microbiol. 8:279. doi: 10.3389/fmicb.2017.00279
Peng, S., Kong, D., Li, L., Zou, C., Chen, F., Li, M., et al. (2020). Distribution and sources of DDT and its metabolites in porewater and sediment from a typical tropical bay in the South China Sea. Environ. Pollut. 267:115492. doi: 10.1016/j.envpol.2020.115492

Pérez-Armendáriz, B., Cal-y-Mayor-Luna, C., El-Kassis, E. G., and OrtegaMartínez, L. D. (2019). Use of waste canola oil as a low-cost substrate for rhamnolipid production using Pseudomonas aeruginosa. AMB Express 9, 1-9. doi: 10.1186/s13568-019-0784-7

Piumini, M., Liyanage, S., Bogahawaththa, T., Perera, I., and Mallawaarachchi, V. (2021). "EasyBin: metagenomics binning services for non-specialists," in Proceedings of the 2021 Moratuwa Engineering Research Conference (MERCon), Moratuwa, 687-692.

Prihandiani, A., Bella, D. R., Chairani, N. R., Winarto, Y., and Fox, J. (2021). The tsunami of pesticide use for rice production on Java and its consequences. Asia Pac. J. Anthropol. 22, 276-297.

Purnomo, A. S., Ashari, K., and Hermansyah, F. T. (2017). Evaluation of the synergistic effect of mixed cultures of white-rot fungus pleurotus ostreatus and biosurfactant-producing bacteria on DDT biodegradation. J. Microbiol. Biotechnol. 27, 1306-1315. doi: 10.4014/jmb.1701.01073

Rajesh, M., Samundeeswari, M., and Archana, B. (2017). Isolation of biosurfactant producing bacteria from garbage soil. J. Appl. Environ. Microbiol. 5, 74-78. doi: 10.12691/jaem-5-2-3

Ramirez, C. A. O., Kwan, A., and Li, Q. X. (2020). Rhamnolipids induced by glycerol enhance dibenzothiophene biodegradation in Burkholderia sp. C3. Engineering 6, 533-540.

Rasheed, T., Shafi, S., Bilal, M., Hussain, T., Sher, F., and Rizwan, K. (2020). Surfactants-based remediation as an effective approach for removal of environmental pollutants-a review. J. Mol. Liq. 318:113960. doi: 10.1016/j. molliq.2020.113960

Ravula, A. R., and Yenugu, S. (2021). Pyrethroid based pesticides-chemical and biological aspects. Crit. Rev. Toxicol. 51, 117-140. doi: 10.1080/10408444.2021. 1879007

Rawat, G., Dhasmana, A., and Kumar, V. (2020). Biosurfactants: the next generation biomolecules for diverse applications. Environ. Sustain. 3, 353-369. doi: 10.1007/s42398-020-00128-8

Rodríguez, A., Castrejón-Godínez, M. L., Salazar-Bustamante, E., Gama-Martínez, Y., Sánchez-Salinas, E., Mussali-Galante, P., et al. (2020). Omics approaches to pesticide biodegradation. Curr. Microbiol. 77, 545-563. doi: 10.1007/s00284020-01916-5

Rosenberg, M., Gutnick, D., and Rosenberg, E. (1980). Adherence of bacteria to hydrocarbons: a simple method for measuring cell-surface hydrophobicity. FEMS Microbiol. Lett. 9, 29-33. doi: 10.1111/j.1574-6968.1980.tb05599.x

Sachdev, D. P., and Cameotra, S. S. (2013). Biosurfactants in agriculture. Appl. Microbiol. Biotechnol. 97, 1005-1016. doi: 10.1007/s00253-012-4641-8

Saharan, B. S., Sahu, R. K., and Sharma, D. (2011). A review on biosurfactants: fermentation, current developments and perspectives. Genet. Eng. Biotechnol. J. 2011, 1-14. doi: 10.1016/j.chemosphere.2021.132574

Santos, D. K. F., Rufino, R. D., Luna, J. M., Santos, V. A., and Sarubbo, L. A. (2016). Biosurfactants: multifunctional biomolecules of the 21st century. Int. J. Mol. Sci. 17, 401. doi: 10.3390/ijms17030401

Sarath Chandran, C., Thomas, S., and Unni, M. R. (2019). "Pesticides: classification, detection, and degradation," in Organic Farming, eds C. Sarath Chandran, S. Thomas, and M. Unni (Cham: Springer). doi: 10.1007/978-3-03004657-6_5

Sarwar, A., Brader, G., Corretto, E., Aleti, G., Abaidullah, M., Sessitsch, A., et al. (2018). Qualitative analysis of biosurfactants from Bacillus species exhibiting antifungal activity. PLoS One 13:e0198107. doi: 10.1371/journal.pone.0198107

Satpute, S. K., Banpurkar, A. G., Dhakephalkar, P. K., Banat, I. M., and Chopade, B. A. (2010). Methods for investigating biosurfactants and bioemulsifiers: a review. Crit. Rev. Biotechnol. 30, 127-144. doi: 10.3109/07388550903427280

Scheuch, M., Höper, D., and Beer, M. (2015). RIEMS: a software pipeline for sensitive and comprehensive taxonomic classification of reads from metagenomics datasets. BMC Bioinformatics 16:69. doi: 10.1186/S12859-0150503-6

Schubert, M., Ermini, L., Sarkissian, C., Jónsson, H., Ginolhac, A., Schaefer, R., et al. (2014). Characterization of ancient and modern genomes by SNP detection and phylogenomic and metagenomic analysis using PALEOMIX. Nat. Protoc. 9, 1056-1082. doi: 10.1038/nprot.2014.063 
Schultz, J., and Rosado, A. S. (2020). Extreme environments: a source of biosurfactants for biotechnological applications. Extremophiles 24, 189-206. doi: 10.1007/s00792-019-01151-2

Sebby, K. (2010). The Green Revolution of the 1960's and Its Impact on Small Farmers in India. Environmental Studies Undergraduate Student Theses. Lincoln, NE: University of Nebraska-Lincoln.

Sekhon, K. K., Khanna, S., and Cameotra, S. S. (2011). Enhanced biosurfactant production through cloning of three genes and role of esterase in biosurfactant release. Microb. Cell Fact. 10:49. doi: 10.1186/1475-2859-10-49

Semai, A., Plewniak, F., Charrié-Duhaut, A., Sayeh, A., Gil, L., Vandecasteele, C., et al. (2021). Characterisation of hydrocarbon degradation, biosurfactant production, and biofilm formation in Serratia sp. Tan611: a new strain isolated from industrially contaminated environment in Algeria. Antonie Van Leeuwenhoek 114, 411-424. doi: 10.1007/s10482-021-01527-5

Sequinatto, L., Reichert, J. M., Dos Santos, D. R., Reinert, D. J., and Copetti, A. C. C. (2013). Occurrence of agrochemicals in surface waters of shallow soils and steep slopes cropped to tobacco. Quim. Nova 36, 768-772. doi: 10.1590/S010040422013000600004

Shabbir, M., Singh, M., Maiti, S., Kumar, S., and Saha, S. K. (2018). Removal enactment of organo-phosphorous pesticide using bacteria isolated from domestic sewage. Bioresour. Technol. 263, 280-288. doi: 10.1016/j.biortech. 2018.04.122

Shah, N., Molloy, E. K., Pop, M., and Warnow, T. (2021). TIPP2: metagenomic taxonomic profiling using phylogenetic markers. Bioinformatics 37, 1839-1845. doi: 10.1093/bioinformatics/btab023

Sharma, A., Kumar, V., Shahzad, B., Tanveer, M., Sidhu, G. P. S., Handa, N., et al. (2019). Worldwide pesticide usage and its impacts on ecosystem. SN Appl. Sci. 1:1446. doi: 10.1007/S42452-019-1485-1

Sharma, A., Shukla, A., Attri, K., Kumar, M., Kumar, P., Suttee, A., et al. (2020). Global trends in pesticides: a looming threat and viable alternatives. Ecotoxicol. Environ. Saf. 201:110812. doi: 10.1016/j.ecoenv.2020.110812

Sharma, D., Singh Saharan, B., Chauhan, N., Procha, S., and Lal, S. (2015). Isolation and functional characterization of novel biosurfactant produced by Enterococcus faecium. Springerplus 4:4. doi: 10.1186/2193-1801-4-4

Sharma, P., Kumar, S., and Pandey, A. (2021). Bioremediated techniques for remediation of metal pollutants using metagenomics approaches: a review. J. Environ. Chem. Eng. 9:105684. doi: 10.1007/398_2019_24

Shikha, Singh, S., and Shankar, S. (2021). "Microbial metagenomics," in Advances in Animal Genomics, eds S. Mondal and R. L. Singh (Amsterdam: Elsevier), 109-122. doi: 10.1016/b978-0-12-820595-2.00008-4

Siegmund, I., and Wagner, F. (1991). New method for detecting rhamnolipids excreted by Pseudomonas species during growth on mineral agar. Biotechnol. Tech. 5, 265-268. doi: 10.1007/BF02438660

Singh, A., Van Hamme, J. D., and Ward, O. P. (2007). Surfactants in microbiology and biotechnology: part 2. Application aspects. Biotechnol. Adv. 25, 99-121. doi: 10.1016/j.biotechadv.2006.10.004

Singh, A. K., Bilal, M., Iqbal, H. M., and Raj, A. (2021). Trends in predictive biodegradation for sustainable mitigation of environmental pollutants: recent progress and future outlook. Sci. Total Environ. 770:144561. doi: 10.1016/j. scitotenv.2020.144561

Singh, J. S. (2015). Microbes: the chief ecological engineers in reinstating equilibrium in degraded ecosystems. Agric. Ecosyst. Environ. 203, 80-82. doi: 10.1016/j.agee.2015.01.026

Singh, J. S., Abhilash, P. C., Singh, H. B., Singh, R. P., and Singh, D. P. (2011). Genetically engineered bacteria: an emerging tool for environmental remediation and future research perspectives. Gene 480, 1-9. doi: 10.1016/j. gene.2011.03.001

Singh, J. S., and Gupta, V. K. (2018). Soil microbial biomass: a key soil driver in management of ecosystem functioning. Sci. Total Environ. 634, 497-500. doi: 10.1016/j.scitotenv.2018.03.373

Singh, M. J., and Sedhuraman, P. (2015). Biosurfactant, polythene, plastic, and diesel biodegradation activity of endophytic Nocardiopsis sp. mrinalini9 isolated from Hibiscus rosasinensis leaves. Bioresour. Bioprocess. 2, 1-7. doi: 10.1186/ S40643-014-0034-4

Singh, M. K., Rai, P. K., Rai, A., Singh, S., and Singh, J. S. (2019). Poly$\beta$-hydroxybutyrate production by the cyanobacterium Scytonema geitleri Bharadwaja under varying environmental conditions. Biomolecules 9:198. doi: 10.3390/biom 9050198
Singh, P., Saini, H. S., and Raj, M. (2016). Rhamnolipid mediated enhanced degradation of chlorpyrifos by bacterial consortium in soilwater system. Ecotoxicol. Environ. Saf. 134, 156-162. doi: 10.1016/j.ecoenv. 2016.07.020

Singh, P. B., Sharma, S., Saini, H. S., and Chadha, B. S. (2009). Biosurfactant production by Pseudomonas sp. and its role in aqueous phase partitioning and biodegradation of chlorpyrifos. Lett. Appl. Microbiol. 49, 378-383. doi: 10.1111/j.1472-765X.2009.02672.x

Singh, S., Singh, H., Rout, B., Tripathi, R. B. M., Chopra, C., and Chopra, R. S. (2020b). "The new science of metagenomics: revealing the secrets of microbial physiology," in Metagenomics: Techniques, Applications, Challenges and Opportunities, eds R. S. Chopra, C. Chopra, and N. R. Sharma (Singapore: Springer), 3-22. doi: 10.1007/978-981-15-6529-8_1

Singh, S., Kumar, V., Singh, S., Dhanjal, D. S., Datta, S., Sharma, D., et al. (2020a). "Biosurfactant-based bioremediation," in Bioremediation of Pollutants, eds V. C. Pandey and V. Singh (Amsterdam: Elsevier), 333-358. doi: 10.1016/b978-0-12819025-8.00016-8

Soares da Silva, R. C. F., de Almeida, D. G., Brasileiro, P. P. F., Rufino, R. D., de Luna, J. M., and Sarubbo, L. A. (2019). Production, formulation and cost estimation of a commercial biosurfactant. Biodegradation 30, 191-201. doi: 10.1007/s10532-018-9830-4

Soberón-Chávez, G., Lépine, F., and Déziel, E. (2005). MINI-REVIEW production of rhamnolipids by Pseudomonas aeruginosa. Appl. Microbiol. Biotechnol. 68, 718-725. doi: 10.1007/s00253-005-0150-3

Soltanighias, T., Singh, A. E. A., Satpute, S. K., Banpurkar, A. G., Koolivand, A., and Rahi, P. (2019). Assessment of biosurfactant-producing bacteria from oil contaminated soils and their hydrocarbon degradation potential. Environ. Sustain. 2, 285-296. doi: 10.1007/s42398-019-00074-0

Sponza, D. T., and Gok, O. (2011). Effects of sludge retention time and biosurfactant on the treatment of polyaromatic hydrocarbon (PAH) in a petrochemical industry wastewater. Water Sci. Technol. 64, 2282-2292. doi: 10.2166/wst.2011.734

Sun, M., Ye, M., Wu, J., Feng, Y., Shen, F., Tian, D., et al. (2015). Impact of bioaccessible pyrene on the abundance of antibiotic resistance genes during Sphingobium sp.- and sophorolipid-enhanced bioremediation in soil. J. Hazard. Mater. 300, 121-128. doi: 10.1016/j.jhazmat.2015.0 6.065

Tamames, J., and Puente-Sánchez, F. (2019). SqueezeMeta, a highly portable, fully automatic metagenomic analysis pipeline. Front. Microbiol. 9:3349. doi: 10. 3389/FMICB.2018.03349

Tan, Y. N., and Li, Q. (2018). Microbial production of rhamnolipids using sugars as carbon sources. Microb. Cell Factor. 17, 1-13. doi: 10.1016/b978-0-12-8218822.00009-0

Taş, N., de Jong, A. E., Li, Y., Trubl, G., Xue, Y., and Dove, N. C. (2021). Metagenomic tools in microbial ecology research. Curr. Opin. Biotechnol. 67, 184-191.

Tchounwou, P. B., Patlolla, A. K., Yedjou, C. G., and Moore, P. D. (2015). Environmental exposure and health effects associated with malathion toxicity. Toxic. Hazard Agrochem. 51, 2145-2149.

Thavasi, R., Jayalakshmi, S., and Banat, I. M. (2011). Application of biosurfactant produced from peanut oil cake by Lactobacillus delbrueckii in biodegradation of crude oil. Bioresour. Technol. 102, 3366-3372. doi: 10.1016/j.biortech.2010.11. 071

Thies, S., Rausch, S. C., Kovacic, F., Schmidt-Thaler, A., Wilhelm, S., Rosenau, F., et al. (2016). Metagenomic discovery of novel enzymes and biosurfactants in a slaughterhouse biofilm microbial community. Sci. Rep. 6:27035. doi: 10.1038/ srep27035

Touseef, H., and Ahmad, K. A. (2018). A combination of rapid and easy assays of biosurfactant producing bacterial strain isolated from automobiles repairing workshop in Aligarh. Proc. Voronezh State Univ. Eng. Technol. 80:77.

Treangen, T. J., Koren, S., Sommer, D. D., Liu, B., Astrovskaya, I., Ondov, B., et al. (2013). MetAMOS: a modular and open source metagenomic assembly and analysis pipeline. Genome Biol. 14:R2. doi: 10.1186/GB-2013-14-1-R2

Tripathi, L., Twigg, M. S., Zompra, A., Salek, K., Irorere, V. U., Gutierrez, T., et al. (2019). Biosynthesis of rhamnolipid by a Marinobacter species expands the paradigm of biosurfactant synthesis to a new genus of the marine microflora. Microb. Cell Fact. 18, 1-12. doi: 10.1186/s12934-019-1216-8 
Truong, D., Franzosa, E., Tickle, T., Scholz, M., Weingart, G., Pasolli, E., et al. (2015). MetaPhlAn2 for enhanced metagenomic taxonomic profiling. Nat. Methods 12, 902-903. doi: 10.1038/nmeth.3589

Tsuge, K., Ohata, Y., and Shoda, M. (2001). Gene yerP, involved in surfactin selfresistance in Bacillus subtilis. Antimicrob. Agents Chemother. 45, 3566-3573. doi: 10.1128/AAC.45.12.3566-3573.2001

Twigg, M., Tripathi, L., Zompra, K., Salek, K., Irorere, V., Gutierrez, T., et al. (2019). Surfactants from the sea: rhamnolipid production by marine bacteria. Access Microbiol. 1:192. doi: 10.1099/acmi.ac2019.po0066

U.S. Environmental Protection Agency | US EPA (2021). EPA \& The Bipartisan Infrastructure Law. Available online at: https://www.epa.gov/ (accessed December 2, 2021).

Uritskiy, G. V., DiRuggiero, J., and Taylor, J. (2018). MetaWRAP—a flexible pipeline for genome-resolved metagenomic data analysis. Microbiome 6:158. doi: 10.1186/S40168-018-0541-1

Uzoigwe, C., Burgess, J. G., Ennis, C. J., and Rahman, P. K. S. M. (2015). Bioemulsifiers are not biosurfactants and require different screening approaches. Front. Microbiol. 6:245. doi: 10.3389/ FMICB.2015.00245/FULL

Varjani, S., Rakholiya, P., Ng, H. Y., Taherzadeh, M. J., Ngo, H. H., Chang, J. S., et al. (2021). Bio-based rhamnolipids production and recovery from waste streams: status and perspectives. Bioresour. Technol. 319:124213. doi: 10.1016/j.biortech. 2020.124213

Varjani, S. J., and Upasani, V. N. (2016). Core Flood study for enhanced oil recovery through ex-situ bioaugmentation with thermo- and halo-tolerant rhamnolipid produced by Pseudomonas aeruginosa NCIM 5514. Bioresour. Technol. 220, 175-182. doi: 10.1016/j.biortech.2016.08.060

Varjani, S. J., and Upasani, V. N. (2017). Critical review on biosurfactant analysis, purification and characterization using rhamnolipid as a model biosurfactant. Bioresour. Technol. 232, 389-397. doi: 10.1016/j.biortech.2017.02.047

Walter, V., Syldatk, C., and Hausmann, R. (2010). Screening concepts for the isolation of biosurfactant producing microorganisms. Adv. Exp. Med. Biol. 672, 1-13. doi: 10.1007/978-1-4419-5979-9_1

Wattanaphon, H. T., Kerdsin, A., Thammacharoen, C., Sangvanich, P., and Vangnai, A. S. (2008). A biosurfactant from Burkholderia cenocepacia BSP3 and its enhancement of pesticide solubilization. J. Appl. Microbiol. 105, 416-423. doi: 10.1111/j.1365-2672.2008.03755.x

Whang, L. M., Liu, P. W. G., Ma, C. C., and Cheng, S. S. (2009). Application of rhamnolipid and surfactin for enhanced diesel biodegradation-effects of $\mathrm{pH}$ and ammonium addition. J. Hazard. Mater. 164, 1045-1050. doi: 10.1016/j.jhazmat. 2008.09.006

Williams, W., and Trindade, M. (2017). "Metagenomics for the discovery of novel biosurfactants," in Functional Metagenomics: Tools and Applications, eds T. C. Charles, M. R. Liles, and A. Sessitsch (Cham: Springer International Publishing), 95-117. doi: 10.1007/978-3-319-61510-3_6

Wu, S., Zhu, Z., Fu, L., Niu, B., and Li, W. (2011). WebMGA: a customizable web server for fast metagenomic sequence analysis. BMC Genomics 12:444. doi: 10.1186/1471-2164-12-444

Xu, X., Liu, W., Tian, S., Wang, W., Qi, Q., Jiang, P., et al. (2018). Petroleum hydrocarbon-degrading bacteria for the remediation of oil pollution under aerobic conditions: a perspective analysis. Front. Microbiol. 9:2885. doi: 10. 3389/fmicb. 2018.02885

Yadav, B. S., Yadav, A. K., Singh, S., Singh, N. K., and Mani, A. (2019). "Methods in metagenomics and environmental biotechnology," in Nanoscience and Biotechnology for Environmental Applications, eds K. Gothandam, S. Ranjan, N. Dasgupta, and E. Lichtfouse (Cham: Springer), 85-113.

Yañez-Ocampo, G., Somoza-Coutiño, G., Blanco-González, C., and WongVillarreal, A. (2017). Utilization of agroindustrial waste for biosurfactant production by native bacteria from chiapas. Open Agric. 2, 341-349. doi: 10.1515/opag-2017-0038

Yang, Y., Jiang, X., Chai, B., Ma, L., Li, B., Zhang, A., et al. (2016). ARGsOAP: online analysis pipeline for antibiotic resistance genes detection from metagenomic data using an integrated structured ARG-database. Bioinformatics 32, 2346-2351. doi: 10.1093/bioinformatics/btw136

Yoshikawa, M., Zhang, M., and Toyota, K. (2017). Minireview biodegradation of volatile organic compounds and their effects on biodegradability under co-existing conditions. Microbes Environ. 32, 188-200. doi: 10.1264/jsme2. ME16188

Youssef, N. H., Duncan, K. E., Nagle, D. P., Savage, K. N., Knapp, R. M., and McInerney, M. J. (2004). Comparison of methods to detect biosurfactant production by diverse microorganisms. J. Microbiol. Methods 56, 339-347. doi: 10.1016/j.mimet.2003.11.001

Yu, H., and Huang, G. H. (2011). Isolation and characterization of biosurfactantand bioemulsifier-producing bacteria from petroleum contaminated sites in Western Canada. Soil Sedim. Contam. 20, 274-288. doi: 10.1080/15320383. 2011.560981

Zhang, C., Wang, S., and Yan, Y. (2011). Isomerization and biodegradation of betacypermethrin by Pseudomonas aeruginosa $\mathrm{CH} 7$ with biosurfactant production. Bioresour. Technol. 102, 7139-7146. doi: 10.1016/j.biortech.2011.03.086

Zhou, M. F., Yuan, X. Z., Zhong, H., Liu, Z. F., Li, H., Jiang, L. L., et al. (2011). Effect of biosurfactants on laccase production and phenol biodegradation in solid-state fermentation. Appl. Biochem. Biotechnol. 164, 103-114. doi: 10.1007/ s12010-010-9118-6

Conflict of Interest: The authors declare that the research was conducted in the absence of any commercial or financial relationships that could be construed as a potential conflict of interest.

Publisher's Note: All claims expressed in this article are solely those of the authors and do not necessarily represent those of their affiliated organizations, or those of the publisher, the editors and the reviewers. Any product that may be evaluated in this article, or claim that may be made by its manufacturer, is not guaranteed or endorsed by the publisher.

Copyright (c) 2021 Raj, Kumar and Dames. This is an open-access article distributed under the terms of the Creative Commons Attribution License (CC BY). The use, distribution or reproduction in other forums is permitted, provided the original author(s) and the copyright owner(s) are credited and that the original publication in this journal is cited, in accordance with accepted academic practice. No use, distribution or reproduction is permitted which does not comply with these terms. 